$F E-15601-37$

Dist. Category UC $-90 \mathrm{~g}$

DOE/ET/ $15601--37$

DE91 006899

\title{
DIAGNOSTIC DEVELOPMENT AND SUPPORT \\ OF MHD TEST FACILITIES
}

\author{
Technical Progress Report \\ for the period \\ April, May, June 1989
}

W. S. Shepard, Director

R. L. Cook, Deputy Director

\section{Diagnostic Instrumentation and Analysis Laboratory Mississippi State University \\ Mississippi State, Mississippi 39762}

Date Published: July 1989

\author{
Prepared for the United States \\ Department of Energy \\ Under Contract No. DE-ACO2-8QET-15601
}


This report was prepared as an account of work sponsored by the United States Government. Neither the United States nor the United States Department of Energy, nor any of their employees, makes any warranty, expressed or implied, or assumes any legal liability or responsibility for the accuracy, completeness, or usefulness of any information, apparatus, product, or process disclosed, or represents that its use would not infringe privately owned rights. Reference herein to any specific commercial product, process, or service by trade name, mark, manufacturer, or otherwise, does not necessarily constitute or imply its endorsement, recommendation, or favoring by the United States Government or any agency thereof. The views and opinions of authors expressed herein do not necessarily state or reflect those of the United States Government or any agency thereof. 
List of figures... . . . . . . . . . . . . . . . . . iv

List of Tables . . . . . . . . . . . . . . . . . . v

Nomenclature. . . . . . . . . . . . . . . . . . . . vi

Abstract. . . . . . . . . . . . . . . . . . . . 1

Statement of Work . . . . . . . . . . . . . . . . . . . 2

Objective . . . . . . . . . . . . . . . . . . 2

Scope of Work . . . . . . . . . . . . . . . . . 3

Description of Facilities................... . . 10

Technical Progress. . . . . . . . . . . . . . . . . . . . 11

Task 1. Instrumentation Development. . . . . . . . . . . . . 12

A. Coherent Anti-Stokes Raman Spectroscopy System (CARS) . . . . . . . . . . . . . . . . . . 12

B. Particle Size Distribution System (PSD) . . . . . . . . . . 18

C. Potassium Emission/Absorption System (PE/AS). . . . . . . . . 26

D. Intrusive Multi-Probe System (IMPS) . . . . . . . . . . . . . 43

E. Faraday Rotation System (FRS) . . . . . . . . . . . . 4 46

F. Multi-Purpose Imaging System (MPIS) . . . . . . . . . . . . . 47

Task 2. Test Stand Operations. . . . . . . . . . . . . . . . 50

A. Test Stand Modifications. . . . . . . . . . . . . . . . 50

B. Computer Control Up-grade . . . . . . . . . . . . . . . 50

C. Test Stand Runs... . . . . . . . . . . . . . . . . . 50

Task 3. Support for the National MHD Program . . . . . . . . . . . 52

A. Field Measurements. . . . . . . . . . . . . . . . . 52

B. Field Tests/Instrument Modifications. . . . . . . . . . . . . 52

c. Mobile Instrument Laboratory. . . . . . . . . . . . . . . . 52

Task 4. Project Management . . . . . . . . . . . . . . 53

Task 5. Technology Transfer. . . . . . . . . . . . . . . 54 


\section{LIST OF FIGURES}

1.A.1. Schematic diagram of the data acquisition/analysis system . . . 13

1.A.2. $\mathrm{N}_{2}$ CARS spectrum in the air with the mobile CARS system . . . . 15

1.A.3. $\mathrm{N}_{2}$ CARS spectrum recorded in a furnace at $1470 \mathrm{~K}$. . . . . . . . 16

1.B.1. Simulation results for uniform distribution 1-10 $\mu \mathrm{m} . \ldots 19$

1.B.2. Simulation results for uniform distribution 1-10 $\mu \mathrm{m}$. . . . . . . 20

1.B.3. Simulation results for uniform distribution $1-1 u \mu m$. . . . . . . 22

1.C.1. Design for the optical port assembly for the coal-fired combustion tests at the CDIF . . . . . . . . 27

1.C.2. Sodium multi-wavelength line reversal results for the CFC-2 test on March 29, 1989. . . . . . . . . . . . . . . . . 29

1.C.3. Pictures of the optical windows following tests CFC-2 and CFC-3..................... 31

1.C.4. Sodium multi-wavelength line reversal results for the CFC-3 test on March 31, 1989. . . . . . . . . . . . . . . . . 32

1.C.5. Potassium multi-wavelength line reversal results for the CFC-3 test on March 31, 1989. . . . . . . . . . . . . 33

1.C.6. Spectral scan of the coal-fired flow combustion emission using the vidicon/detector of the PEAS for test CFC-4 on ApriT 5, 1989 . . . . . . . . . . . . . . . . . 34

1.C.7. Potassium D-line emission absorption measurement of gas temperature for the CDIF CFC-11 test on May 15 and 16, 1989 ................. . . 36

1.C.8. Potassium D-line emission absorption measurement of neutral seed atom density for the CDIF CFC-11 test on May 15 and 16, 1989. . . . . . . . . . . . . . . . . . 37

1.C.9. Potassium D-Tine emission absorption measurement of gas temperature for the CDIF CFC-11 test on May 19, 1989. . . . . . . . . . . . . . . . . . . . . . . . . . . 38

1.C.10. Potassium D-1ine emission absorption measurement of neutral seed atom density for the CDIF CFC-11 test

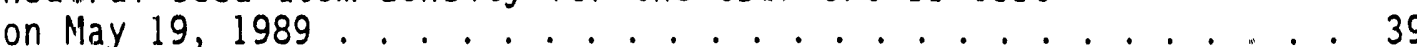

1.C.11. Potassium D-1ine emission absorption measurement of gas temperature for the CFFF LMF4-Q test on May 31, 1989......................... 40

1.C.12. Potassium D-1ine emission absorption measurement of neutral seed atom density for the CFFF LMF4-Q test on May 31, 1989 ....................... . . 41

1.D.1. Furnace wall surface temperature at Penetration 2225 LMF4-Q DOE/CFFF. . . . . . . . . . . .......... . 44

1.F.l. Potassium fluorescence image of seed methane/air flame. . . . . 48 


\section{LIST OF TABLES}

2.C.1. Test stand runs, Apri1-June, 1989................ 51 
NOMENCLATURE

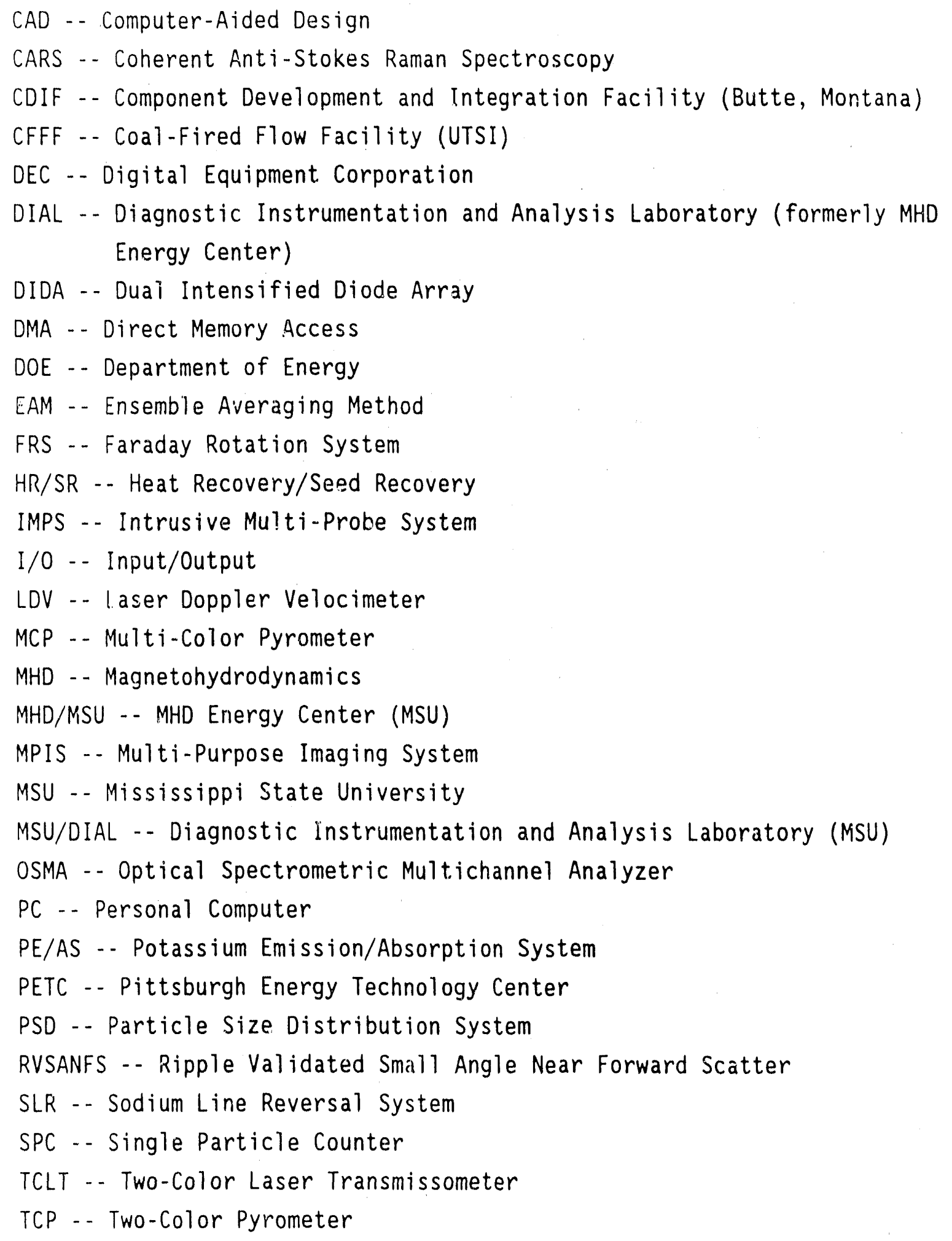


USED (CARS) -- Unstable-Resonator Soatially Enhanced Detection

UTSI - - University of Tennessee Space Institute (Tullahoma)

UV - - Ultraviolet 


\section{ABSTRACT}

Mississippi State University is developing diagnostic instruments for MHD power train data acquisition and for support of MHD component development test facilities. Microprocessor-controlled optical instruments, initially developed for HRSR support, are being refined, and new systems to measure temperatures and gas-seed-slag stream characteristics are being developed. To further data acquisition and analysis capabilities, the diagnostic systems are being interfaced with MHD Energy Center computers. Technical support for the diagnostic needs of the national MHD research effort is being provided. MSi personnel will also cooperate with government agencies and private industries to improve the transformation of research and development results into processes, products and services applicable to their needs. 
objective

Knowledge of many properties of the MHD operating system is required to find solutions to technological barriers. It is desirable to measure gas temperature, wall temperature, gas velocity, particle size, plasma conductivity, gas composition and other engineering parameters. Conventional instrumentation is of limited use in characterizing these properties, so new instrumentation is required. MSU is developing intrusive and non-intrusive diagnostic instrumentation to characterize the MHD gas stream and provide direct instrumentation support to the various DOE MHD test facilities.

A number of the diagnostic systems already developed will be used for field measurements at the HRSR and MHD power train facilities. The amount of direct diagnostic support of the MHD engineering development test facilities will be as directed by the Department of Energy. Additional diagnostic systems will be developed to provide field-use instruments. Field tests for system refinements of these instrumentation systems will be conducted on the MSU test stand and various DOE MHD test facilities.

Mississippi State University has constructed a test stand that can simulate the gas-slag-seed stream composition, temperature, and metal/fireside environmental conditions for the radiant furnace, superheater, and other MHD system components. The microprocessor-controlled diagnostic instruments developed are being evaluated on the test stand. Measurements conducted on the test stand also provide useful data for the National MHD program. 
Scope of Work

In order to meet the overall objective, the scope of work to be performed is outlined in the following tasks.

Task 1.0 Diagnostic Instrumentation Development

The following microprocessor-controlled diagnostic instrumentation will be developed for support of the MHD component engineering development. Field tests for system refinements will be conducted. Objectives for the specific instrumentation systems are:

A. Coherent Anti-Stokes Raman Spectroscopy System (CARS)

(measures local gas temperature and major species concentration)

A mobile CARS system will be constructed to allow point gas temperature measurements to be made at the MHD test facilities. By moving the focusing and collecting lenses in tanclem a temperature profile can be obtained. A system with capabilities to measure a profile over some four feet will be designed, thus allowing profile measurements in the downstream test components at the CFFF. Such measurements will provide a useful characterization of the gas stream and important information for testing and further developing heat transfer computer models. The spaiial and temporal variation of the gas temperature at the exit of the CDIF channel will provide important information for MHD system scale-up.

B. Particle Size Distribution System (PSD)

(measures particle size distribution)

Efforts will be directed toward improving the present instrument with respect to performance and portability for field use. The emphasis on performance improvements will focus on expanding the range of particle velocities for which reliable measurements can be obtained. The improvement in portability will be achieved by developing or buying new hardware for the electronic system and computer and for the optical mounting system. Experimental measurements will be made on the MSU test stand and at other MHD test sites. Efforts will be concentrated on 
development of a new ensemble averaging technique which can be used to make measurements of particle size distributions in high velocity flows (i.e., several hundred meters per second.) It is possible to use ensemble averaging of the photomultiplier signals without resolving them into pulses characterized by peak value, pulse width, etc. The measurement data is mathematically translated to a particle size distribution by a deconvolution procedure. Experiments will be conducted comparing the results from the ensemble averaging technique with those obtained with the present single-particle counter instrument. A practical instrument will be developed which can be taken to various MHD facilities for field measurements.

C. Potassium Emission/Absorption System (PE/AS)

(measures time-resolved temperature, K-atom density, and electron density)

The Potassium Emission/Absorption System has achieved the first stage of development as a time-resolved temperature measurement system and will shortiy be available for field use. Efforts will be directed toward the next stage of development of the PE/AS for electron densiiy measurements in or near the MHD channel. The method relies upon fitting the shape of the seed atom emission lines for a determination of neutral seed atom density. Knowledge of the seed atom density and the temperature allows for a statistical equilibrium calculation of the electron density. A laboratory burner capable of heavy seed loadings will be constructed and used for laboratory tests of the electron density measurements in conjunction with an independent method, such as microwave absorption, to verify the measurement method. Subsequently, the system will be field tested and madf available as a channel diagnostic for support of the national MHD program. The PE/AS is a versatile spectroscopic instrument and other diagnostic techniques using the imaging abilities of the vidicon detector will be investigated. 


\section{Intrusive Multi-Probe System (IMPS) \\ (optical temperatuie probes)}

Probe 1: Intrusive, Optical Fiber, Wide Range, Spatial

Wa11 Temperature Probe.

Probe 2: Intrusive, Spatial, SLR, High Gas Temperature Probe.

The first year's efforts will be directed toward developing new concepts and techniques of using wide range, temperature sensitive, optical fiber probes to intrusively measure spatial temperatures of MHD interior walls and components. Also, effort will be directed toward investigating various optical techniques of resolving the signal from the miniature optics required for an intrusive spatial SLR gas temperature probe.

The second year's effort will be directed toward laboratory testing and field use evaluation of the intrusive, spatial, temperature measuring concepts and techniques developed during the first year.

E. Faraday Rotation System (FRS)

(measures electron density)

An alternate method, a Faraday rotation system, will be developed for measurement of electron density in an MHD channe1. The measurement relies upon the rotation of polarization of light as it traverses a magnetic field. Optical access will be required through the MHD channel. Faraday rotation using far-infrared radiation and far-infrared interferometry are the primary methods for electron density measurements of combustion MHD plasmas. Faraday rotation has been suggested as best suited for in-situ measurements on the longer path lengths of all but the small research MHD channels.

Development of a Faraday rotation system will first entail choice of design criteria followed by selection of components and system assembly. The system will require custom design and construction for efficient transfer optics. The system will also require thorough testing on small scale systems and comparison measurements will need to be made. 
F. Multi-Purpose Imaging System (MPIS)

(measures $K$-atom density and pressure orofile)

Recently, a number of imaging methods have been developed which are directly applicable to the turbulent flows present in the MHD power plant. Techniques such as Rayleigh-Mie imaging, laser-induced fluorescence, and pressure gradient mapping yield essentially instantaneous two-dimensional profiles of number density, species concentration, and pressure, respectively. This information, either processed alone or in combination, can describe in some detail the inherent gas characteristics. An instrument will be developed which will permit the rapid determination of number density and either pressure or species concentration in the topping cycle region. The optical configuration of the instrument is novel and the desired profile is selected by alternately processing eilher the Rayleigh-Mie wavelength $(532 \mathrm{~nm})$ or a wavelength specific to the gas species electronic transition, or the $405 \mathrm{~nm} 1$ ine of $K$ for the determination of pressure by LIF. In this manner rapid profiles can be obtained and further processed to yield a wide variety of information. The particular emphasis will be the development of a $\mathrm{K}$ atom density anc pressure profile instrument which will be a very useful channel diagnostic. Also consideration will be given to the possible application of this system for measurement of $\mathrm{OH}$ and measurement of the electron density profile.

Task 2.0. Test Stand Operations

The existing MHD/MSU HR/SR simulation test stand will be employed for support of diagnostic instrumentation development, shakedown, and Evaluation. The test stand will be modified to simulate the MHD gas stream environment. This will further aid in the evaluation of the instruments before they are taken to the MHD engineering development test facilities. Ir particular, the test stand will be modified to burn a fuel $011 /$ coal slurry which will nore accurately simulate a coal fuel MHD combustor. Provisions for an increased flow rate of fuel-air mixture of approximately $40 \%$ will also be made. 
The test stand control and data acquisition computer will be replaced with a niew system that will enhance data collection and control as well as provide much needed memory and disc space.

Task 3.0. Technical Support for the National MHD Program

The MSU MHD Energy Center will continue to provide field measurements at other national MHD facilities on an as-needed basis. The current mobile laboratory will be upgraded and an 18-wheeler type trailer will be equipped to operate as a field iaboratory. As new diagnostic instruments are developed for the field they will be interfaced with the data acquisition system in the trailer.

The objective of this task is to provide diagnostic measurements and support to the National MHD Program. Work will include attendance at quarterly meetings and review and input to technical reports.

The following systems are available for field measurements:

Sodium Line Reversal System (average gas temperature)

Multi-Color Pyrometer System (wall temperature and emissivity)

Two-Color Laser Transmissometer System (average particle size and particle number density)

Laser Doppler Velocimeter System (local velocity, velocity profile and turbulence level)

Gas Analysis System (gas composition, e.g., $\mathrm{Cu}, \mathrm{CO}_{2}, \mathrm{NO}$, etc.).

The following systems will be modified/constructed for field use and will be employed for field tests:

Coherent Anti-Stokes Raman Spectroscopy system llocal gas temperature, temperature profile)

Particle Size Distribution System (particle size distribution)

Potassium Emission/Absorption System (time-resolved temperature, $K$-atom density, electron density) 
Intrusive Multi-Probe System (optical temperature probes - wall and gas temperature)

Faraday Rotation System (electron density)

Multi-Purpose Imaging System (K-atom density, pressure profile).

MSU has already started evaluation of the required instrumentation to control a complete MHD system. As part of the support of the national MHD program, this effort will be expanded to include an evaluation of dynamic characteristics of the complete MHD system when the bottoming cycle is integrated with the topping cycle. Instrumentation will be selected to control the MHD system.

Task 4.0. Project Management

The objective of this task is to provide the required management for accomplishment of the Statement of Work with the proposed resources management reporting as required by DOE Form 537. A Safety Plan will be developed to analyze the risk associated with operation of the test stand and to minimize the potential for injury or equipment damage. As part of this plan, the Contractor's Quality Assurance and Reliability policies and procedures will be incorporated.

\section{Task 5.0. Technology Transfer}

Technology transfer is a congressionally mandated objective of the Federal Government. Various enactments of Congress have the purpose of significantly improving the transformation of research and development results into processes, products, and services that can be applied to state and local government and private sector needs. To ensure the maximum benefits of PETC's and subsequently MSU's investment in research and development, MSU's personnel will cooperate with regional industries to demonstrate the technology for intrusive and non-intrusive diagnostic instrumentation developed for the characterization of MHD systems. However important, this task shall in no way interfere with the mainstream efforts of the MHD program. 


\section{DESCRIPTION OF FACILITIES}

The combustion test stand is a computer-controlled simulation test facility available for the combustion of fuel $0 i 1$ at up to $8001 \mathrm{bm} /$ hour of fuel and air. The air can be preheated to temperatures up to $1100 \mathrm{~K}\left(1520^{\circ} \mathrm{F}\right)$ by electrical resistance heaters. Downstream of the combustor are refractory-lined sections containing access ports on both sides and the top of each section.

The MHD Energy Center test facility has a Hewlett-Packard measurement and control system (HP-1000 minicomputer-based system) with real-time software, graphics, and extensive input-output (I/0) capability. The MHD Energy Center is acquiring a Digital Equipment Corporation VAX 11/780 super-minicomputer, and the staff also has access to the University's Univac 1100/80 computer. Computer modeling hardware consists of a graphics terminal and hard copy unit connected to the University mainframe Univac 1100/80 computer.

The microprocessor development laboratory has two Diversified Technology development systems for developing software and firmware for special purpose microcomputers to be used in controlling diagnostic instruments, signal processing and signal analysis:

Complete laser facilities are available, including YAG and dye lasers, spectrometers and photometers, fiber optics, and other equipment. Discharge lamps, power supplies, vacuum systems, UV optics, monochromators, detectors and processing electronics are also available. In addition, the laboratory has several benchtop laboratory burners controlled by precision gas handling systems.

The department of Electrical Engineering at MSU has the facilities and staff for the design, development and construction of hybrid integrated circuits and printed circuit boards.

The following support facilities are available in the MHD Energy Center: (1) Electronics Shop, (2) Machine Shop, (3) Instrument Shop, and (4) Gas Sampling and Analysis System. 
Minicomputer Operations

The DEC Vax-11/780 system will continue to be used as the primary computer for modeling and large scale data analysis. The spectrum modeling and fitting, program development, and data transfer for the CARS project require the largest portion of the computer time. Other instrument development and refinement projects require continued modeling support; these projects include the Two Color Laser Transmissometer (TCLT), Multi-Color Pyrometer (MCP), Potassium Emission/Absorption System (PE/AS), and Particle Size Distribution System (PSD). Computer resources will be required for data analysis of Laser Doppler Velocimeter (LDV) experiments and for general combustion/heat transfer modeling efforts. 


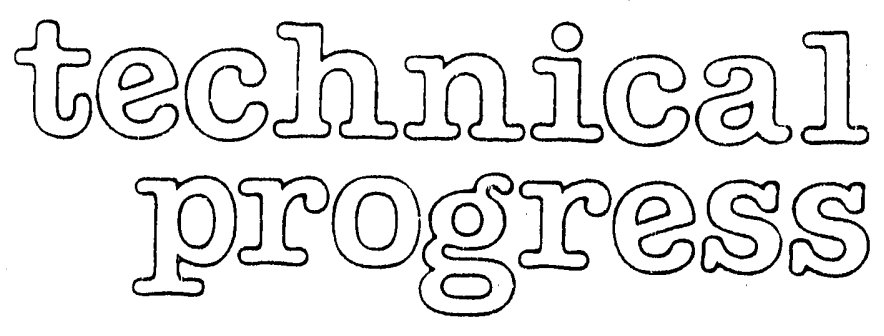


Task 1. Instrumentation Development: R. L. Cook

A. Coherent Anti-Stokes Raman Spectroscopy System (CARS)

J. P. Singh and F. Y. Yueh

Work Performed

The data acquisition computer (VAX-3200) for the mobile CARS system was received, installed and tested. The preliminary test results were satisfactory. The work concentrated on linking this computer system with the data acquisition computer (CompuAdd 386) into a communication network. This network will allow the data collected and stored on the data acquisition computer to be accessed easily by the data analysis computer. The thin wire Ethernet connection between the two computer systems was completed and tested. The VAX/VMS service for MS-DOS software was installed on tre VAX-3200 computer. This software provides remote services to the PC which is connected to the network. With the file services, $P C$ and VAX/VMS users can share data throughout the computer network. The VMS/PCSA Client software was also installed on the hard disk of the CompuAdd computer which configured the $P C$ for the Ethernet communication. The network system is being tested. The data can be transferred and received between these two computer systems transparently. The PC user can also access the printer connected to the VAX-3200 computer through the network.

Since the network between the data acquisition and data analys is computers is completed, testing the complete data acquisition/analysis system is underway. A schematic diagram of the data acquisition/analysis system of the mobile CARS instrument is shown in Figure 1.A.1. The optical fiber brings the CARS signal from the receiver to the spectrograph. The dual intensified diode array (DIDA) detector is mounted on the exit slit of the spectrometer. Since all the detector's elements are exposed simultaneously, an entire spectrum is recorded simultaneously. The ST-120 detector controller provides power thermostating, control, and timing signals to the detector head and provides xyz axis output to an oscilloscope for real-time monitoring. This detector controller was designed to operate exclusively with the IBM compatible computer. An ST-120 software package developed by Princeton Instruments was used for data acquisition, graphics display and data processing. The CARS data will he 


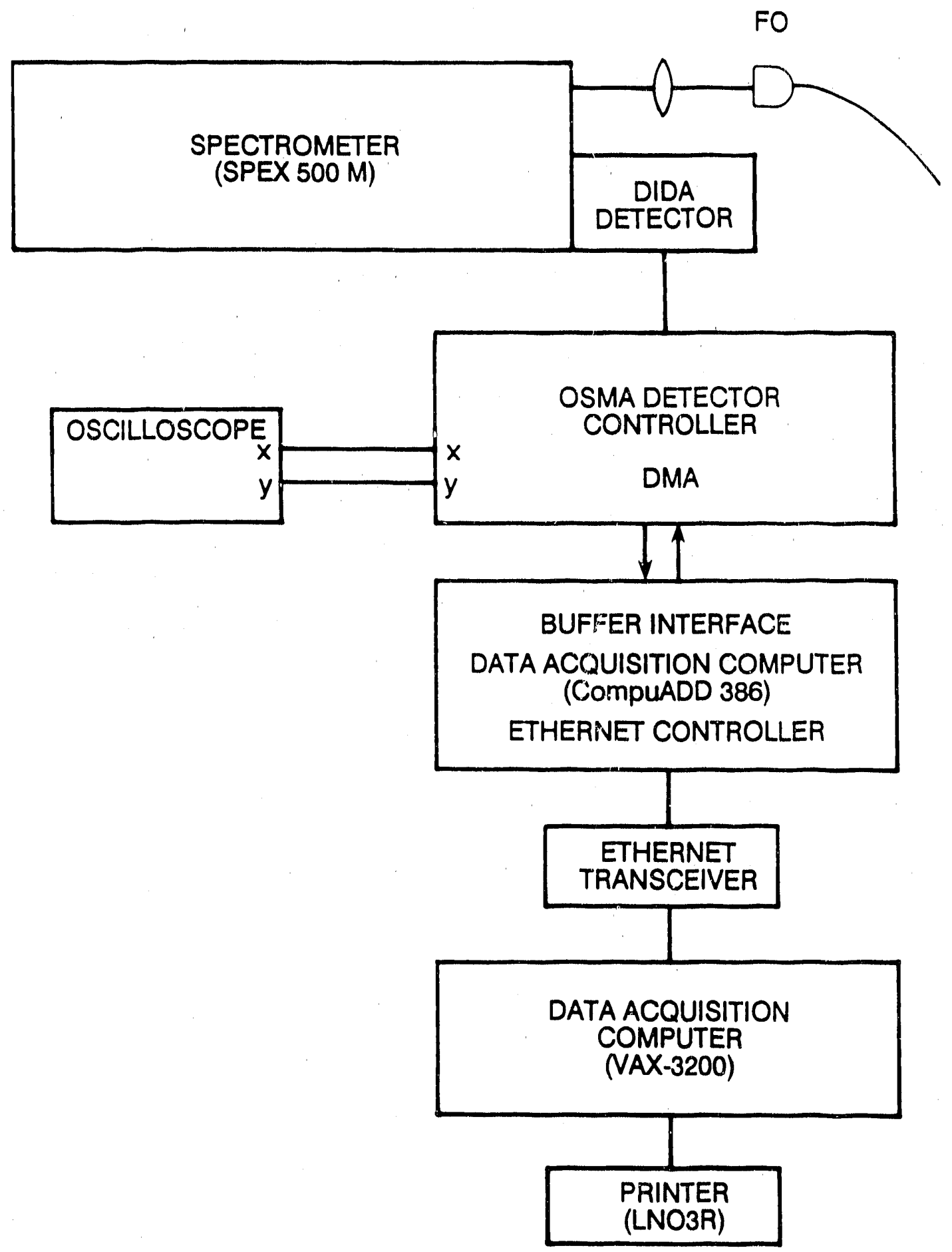

Figure 1.A.1. Schematic diagram of the data acquisition/analysis system. 
collected and stored on the hard disk of the CompuAdd 386 computer. Through the computer network the data are transferred to the VAX-3200 computer for analysis.

To test the receiver and the detector system, $\mathrm{N}_{2}$ CARS spectra were recorded in the air. The receiver which consists of a stack of low wave pass filters, was used to separate the CARS signal from the pump and Stokes lasers. The CARS signal was then piped to a $0.5 \mathrm{~m}$ Spex monochrometer with an optical fiber. It was recorded with an optical spectrometric multichannel analyzer (OSMA) and the CompuAdd computer and then transferred to the VAX station 3200 computer for analysis. Figure 1.A.2 shows a typical $N_{2}$ CARS spectrum recorded in the air with the mobile CARS system using USED CARS phase matching goometry. The shape of this CARS spectrum was different from the one recorded with the laboratory CARS systen. The base of the spectrum has a frequency dependent background. In order to determine the cause of this background, the optical fiber was first tested with the laboratory CARS system.

The CARS signal was generated in a furnace with the laboratory CARS system and piped through an optical fiber to the $0.75 \mathrm{~m}$ Spex monochromator. The temperatures extracted from the fitting of the CARS furnace spectra with computer simulated spectra were in agreement with thermcouple temperatures up to $1100 \mathrm{~K}$. The temperature extracted from CARS data was higher $(\sim 200 \mathrm{~K})$ than the thermocouple temperature at $1470 \mathrm{~K}$. The thermocouple measurements are believed to be accurate to $1 \%$. To compare the data collected using the optical fiber with that collected without the fiber, the $\mathrm{N}_{2}$ CARS spectra were also recorded in the furnace without the optical fiber. Temperatures extracted from the data without the fiber are in agreement with the thermocouple temperatures. Figure 1.A.3 shows the $\mathrm{N}_{2}$ CARS spectra in a furnace at $1470 \mathrm{~K}$ with and without the optical fiber. The higher wavelength side of the CARS spectrum with the optical fiber has higher background than the spectrum without the optical fiber. The reasons for the high background in the long wavelength side of the CARS spectra are not apparent. Further work of this type will continue.

Work on the CO concentration detection 1 imit in the MHD/MSU test stand and on $\mathrm{CO}_{2}$ CARS measurements has been postponed until the test of the mobile CARS system is complete. 


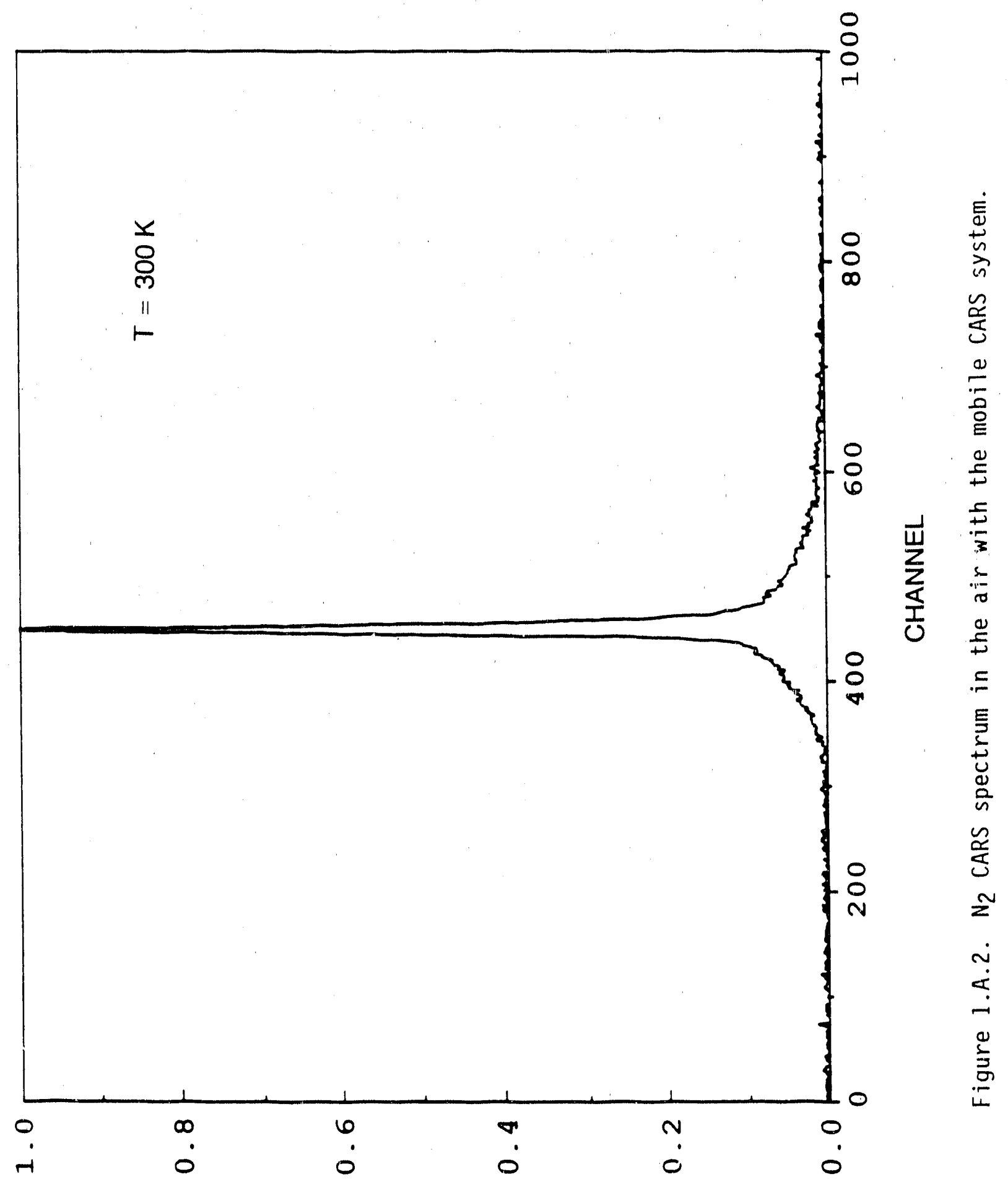

( $\Xi Z Z I 7 \forall W Y O N$ ) ᄉ ISN $\exists \perp N I$ 


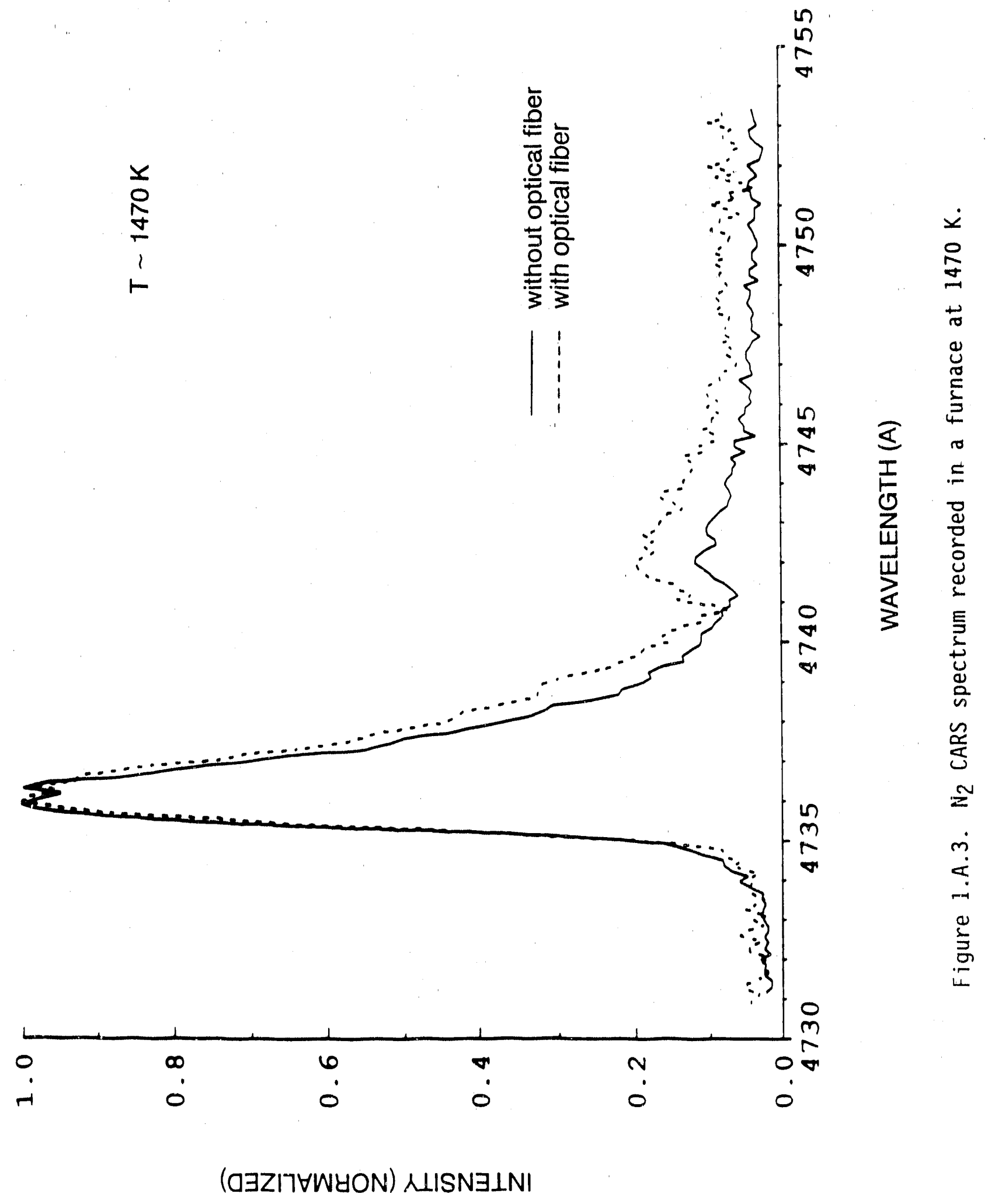




\section{Conclusions}

The communication network of VAX station 3200 and CompuAdd computers of the mobile CARS system performed satisfactorily. The new detection system and optical fiber have introduced some problems to the CARS spectrum which need to be solved for proper operation of the mobile CARS unit in the field.

Work Forecast

Work will continue on solving the problems mentioned in the report. The transmitter and receiver of the mobile CARS system will be tested with CARS data taker in a furnace and the MSU test stand. Testing the data acquisition/analysis system of the mobile CARS system will also continue. 
B. Farticle Size Distribution System (PSD)

J. D. Gassaway

Work Performed

Simulator for Single-Particle Counter (SPC) Instrument: This simulator program, finished earlier, for the SPC instrument was used to simulate several modes and operating conditions. A report is being written which will give a comprehensive description of the simulator and its use. Some of the results of interest are presented here. An earlier quarterly report showed the results obtained for various monodisperse particle size distributions and combinations. 1 Results are given here for discrete distributions which approximate continuous distributions.

Figure 1.B.1 illustrates results for a uniform particle size distribution ranging from one to ten mic ans in size. The simuiation is for the RVSANFS mode of operation discussed earlier 2 for an optical configuration with a receiving angle of approximately two degrees which results in a peak Mie response at $10 \mu \mathrm{m}$ diameter. Figure 1.B.1 (a) illustrates the calculated weighting function for the counts. This is directly proportional to the size increment between adjacent count bins and inversely proportional to the area of an ellipse defining the area in which a particle must be located to generate a validation signal. In this case the size of the validation cross-section is large enough that counts for a given size will be distributed over several bins. Figure 1.B.1 (b) illustrates the observed counts for this simulation condition. The $x$-axis has been transformed from the bin number to the diameter size scale. Figure 1.B.1 (c) illustrates the measured density obtained by dividing counts by the weighting function. Figures 1.B.2 (a-c) show similar results displayed on a bin scale basis. In this case 512 discrete diameter points are used for approximating the continuous distribution, with 2048 count bins which are integrated in groups of 32 , similar to operation of the prototype instrument. Each bin number corresponds to a range of particle diameters as determined by the scattered response, electro-optic sensitivity, etc. Counts may be integrated by summing counts for a number of bins, in this case 32 . This tends to smooth the obs-rved distribution, especially near the end points. 

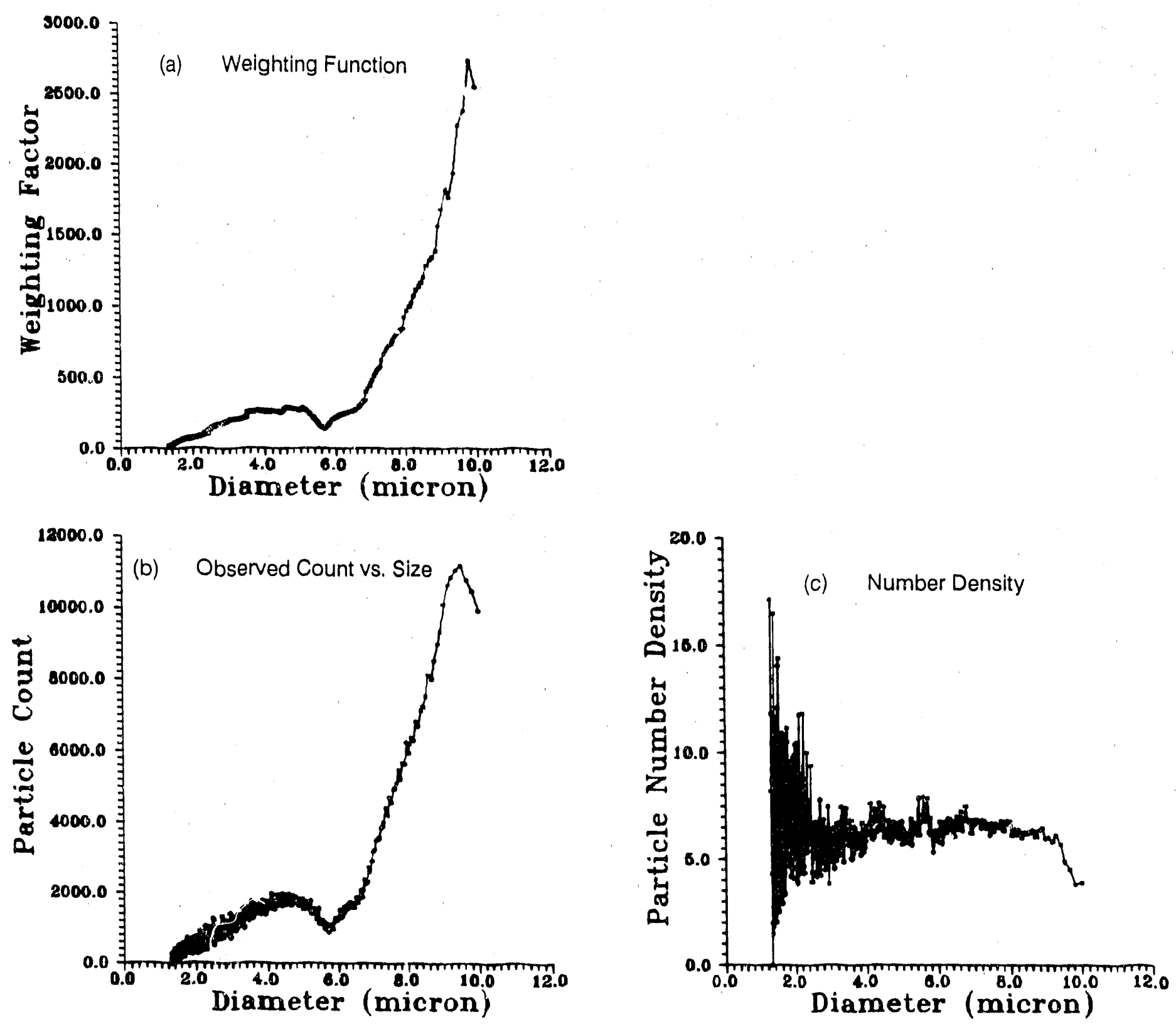

Figure 1.B.1. Simulation results for uniform distribution 1-10 $\mu \mathrm{m}$. 

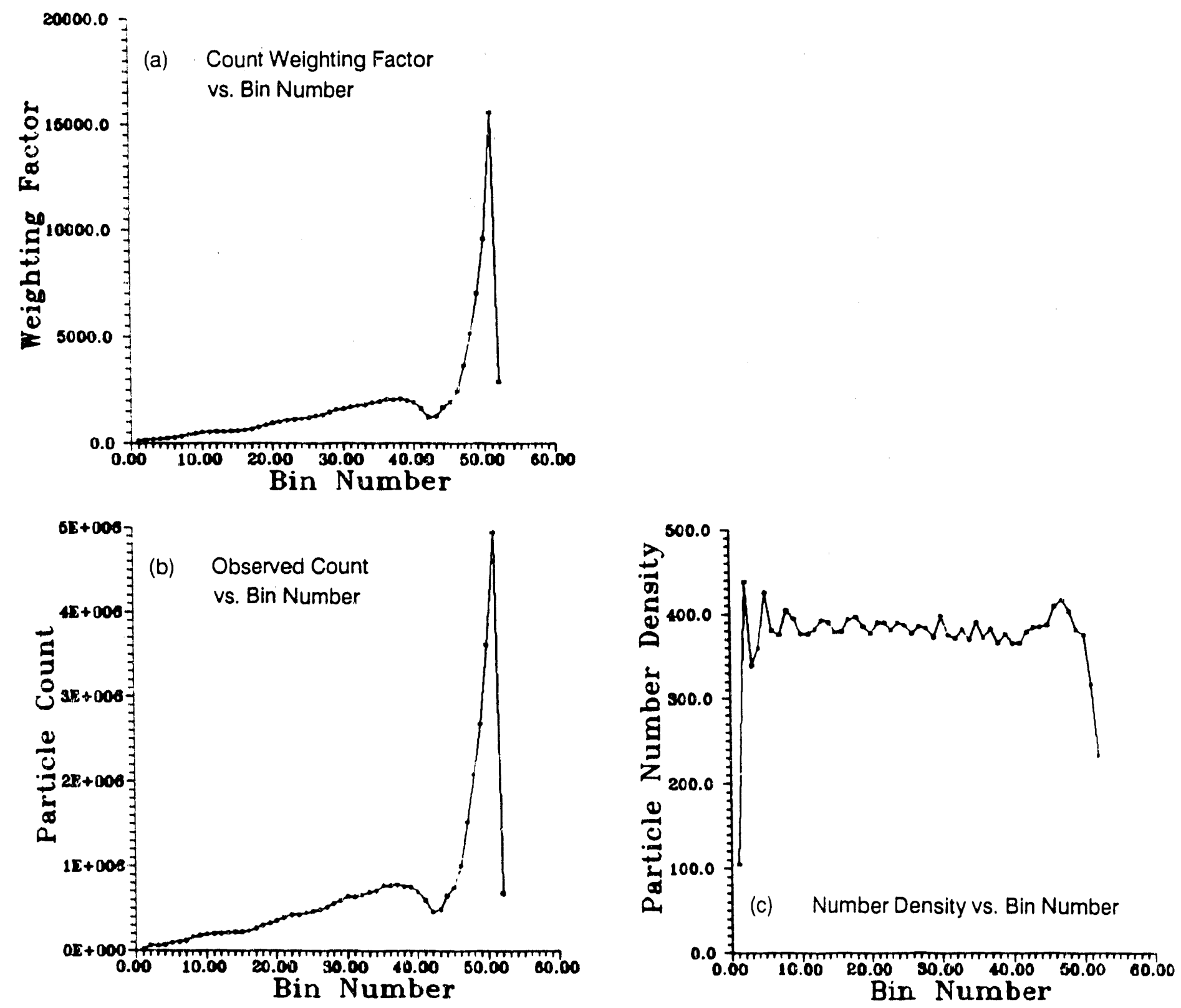

Figure 1.B.2. Simulation results for uniform distribution 1-10 $\mu \mathrm{m}$. 
It is interesting that the silape of the observed count distribution and weighting function are similar. They should be identical for ideal operation in measuring a uniform size distribution. The computed number density function departs somewhat from the uniform input function. The density is systematically high at lower diameters and low at higher diameters. This effect as well as the statistical fluctuation is less noticeable for larger bin groupings as shown in Figure 1.B.2. Figure 1.B.3 illustrates the results obtained when bin count spreading is totally eliminated, as would be the case when the green beam waist is much larger than the blue. Fewer points are used so that the statistical fluctuation is larger, but the systematic error at the scale ends is removed.

Other simulations have been done, and the results will be reported later. These results will be helpful in modifying data reduction algorithms which are developed on the basis of simpler theoretical models that do not include the effects of count spreading. They will also be useful in determining the magnituje of such discrepancies and the importance of controlling them. For example, count spreading in the RVSANFS mode can be controlled by the relative size of the blue beam waist compared with the green, and by the relative settings of the PMT multipliers and comparator thresholds. Use of the latter means is at the expense of a reduced range of sizes that can be measured.

Modeling for the Ensemble Averaging Method (EAM): The basis for this approach and the need for using it were discussed in detail earlier. 1 The nature of the modeling problem was outlined and some results were discussed in the previous quarterly. ${ }^{2}$ The problem of modeling the optical receiver received earlier attention and a useful program was developed for computing the averaged optical response from within a sample volume defined by one of the apertures in the receiver.

Mie scatter calculations were done for the various receiver apertures as well as for different values of the index of refraction. Calculations were done for several different values to determine the importance of this variable in the model. This data will be used in conjunction with earlier modeling data to compute a response matrix for the proposed instrument. Presently, the Mie response curves are being studied for the purpose of choosing the so-called "knot" or "bin" diameters used for the data reduction model. The objective is to choose points on the scale that lead to a well-behaved response matrix. 

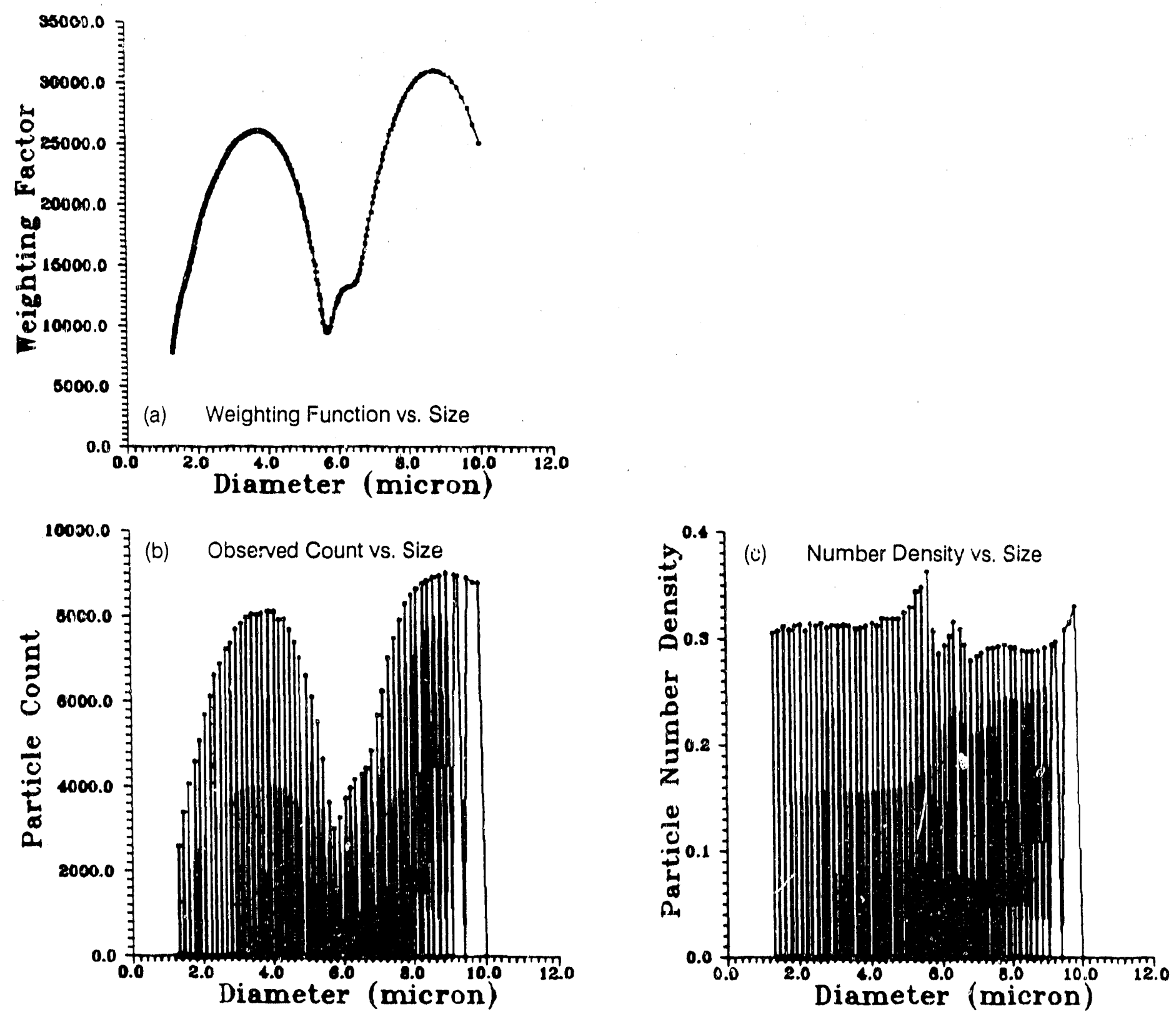

Figure 1.B.3. Simulation results for uniform distribution 1-10 $\mu \mathrm{m}$. 
This seems to require choices that emphasize as few observation angles as possible within one "knot". After this choice is made, the response must be integrated over the range of diameters included in the knot to find the response matrix elements. This requires calculation of scattering cross-sections rather than the Mie amplitude response.

Operating Program for the PSD Field Instrument: No new results were obtained in this effort which has concentrated on debugging of code and testing of the code by operating the computer-instrument interface.

Development of the Instrumentation Optics: All of the optical components have been received. The fiber optics cables and associated hardware were returned to the vendor to correct some deficiencies; however, these should soon be returned. The effort has concentrated mainly on the design of auxiliary beam expanders to increase the diameter of the beams coming from the fibers. The need for expansion of the beams is due to the sample volume size requirements for the expected number densities to be measured. The selective beam expansion for implementing the various operating modes will be done with the same optics used in the prototype instrument. The problem in designing the expander is to obtain precise positioning with mechanisms that fit within an allotted space. Two alternative designs have been developed and one of them will soon be implemented. Some minor items remain to be fabricated for the receiving optics.

Printed Circuit Board Design: Some efforts were directed toward printed circuit board layout using an available computer-aided design (CAD) program as well as hand drawn layouts. It became obvious that this approach was not feasible for the amount of work to be done with the resources available. Consequently, a schematic capture program was obtained which generates input data compatible with a more powerful CAD layout program (a Calay system.) A vendor was identified who can provide the layout service and generate the necessary artwork. Other vendors were identified who can use the artwork to produce both double-sided and multilayered boards. Several of the high frequency boards will be multilayered. This will involve some additional and unanticipated expense which is necessary tc expedite the effort and obtain boards of the quality needed. An additional benefit of the schematic capture program is that it provides a systematic documentation of the design which is ideal for inclusion in a final report on the instrument development. Schematic captures have now 
been done for four of the seven PC boards. A ten day turnaround has been quoted by the artwork vendor, and a four to five week turnaround has been quoted by the PC board fabricator.

\section{Conclusions}

Benefits are now being obtained from development of the simulator program for the SPC type instrument, which is the basis for the field instrument. The effects of count spreading and out-of-range counting due to the multivalued nature of the response can be quantitatively evaluated. The results not only will be helpful in tuning data reduction algorithms but also in defining operating strategies. These issues could be treated only subjectively and empirically in operation of the prototype instrument.

Two of the three major modeling issues for the EAM instrur.ent have been addressed, and the results have been productive. The remaining problem is choice of the "knot diameters" and determination of the response matrix elements. The progress made to this point suggests that the remaining problem will be solved within the next quarter.

The computer operating system program for the field instrument will probably be finished before it is needed.

The optical design problem has been the most difficult but seems near completion. The problem has been complicated by late deliveries of components with unsatisfactory quality. Nevertheless, the conversion to a fiber optics based system is a vital step in development of a viable field instrument. This approach has opened many opportunities for an optical design that is flexible for varied uses and which incorporates the features necessary for on-line optical alignment.

The major problem delaying completion of the signal processor hardware can be solved by use of vendor services. 


\section{Work Forecast}

The emphasis on use of the simulator for the SPC instrument will be concluded during the next quarter and a final report on the simulator will be written. Al1 of the major problems associated with modeling the EAM instrument will have been addressed during the next quarter, with the objective of having a response matrix defined. Due to the amount of activity anticipated in experimental operation of the SPC instrument and because the two approaches share common optical components, little experimental work on the EAM instrument is expected. A firm objective is to finish the optical system for the field instrument and conduct preliminary experimental testing. The printed circuit boards should be finished with at least some of the assembly and testing completed during the next quarter. Work will continue on documentation and preparation of the final report and operations manual for the field instrument.

\section{References}

1. Gassaway, J. D. 1988. DIAL Quarterly Technical Progress Report. 1560-35:14.

2. Gassaway, J. D. 1989. DIAL Quarterly Technical Progress Report. 1560-36:21. 


\section{Potassium Emission/Absorption System (PE/AS) \\ L. E. Bauman}

\section{Work Performed}

The field and Taboratory Potassium Emission/Absorption Systems (PE/AS) were in Butte, Montana at DOE's Component Development and Integration Facility (CDIF) for March, most of April and May and at the University of Tennessee Space Institute in Tullahoma, Tennessee for measurements on DOE's Coal-Fired Flow Facility (CFFF) during May. The test results are summarized here.

The measurements at the CDIF were in support of the coal-fired combustor tests which did not include operation of the channel or injection of potassium seed. A window frame test section was installed downstream of the nozzle for the emission/absorption measurements and this section was followed by the quench ring. Figure 1.C.l shows a view of the optical window assembly and mounting platforms built for these tests. The optical windows were made of BK-7A optical material and were 1.5 inches in diameter and 0.375 inches thick. The PE/AS optical rails were reconfigured with shorter focal length achromat lenses and shorter mounting posts in order to fit into the available :? ear space around the test section. The reference lamp was imaged $1: 1$ at the center of the test section and on the pick-up optical fiber using two $80 \mathrm{~mm}$ focal length lenses.

Tests at the CDIF differed from standard operation of the system in one major respect: two systems were operated through a single reference lamp and associated optics. Doubt about the potassium D-line strength that would be obtained without seeding of the flow contributed to the decision to make this major change after arriving in Butte. Optical fibers for the two systems were stripped of their connectors and mounted as firmly as possible in a single connector for near-coincident, simultaneous light collection. This dual fiber pick-up along with 'teeing' the chopper synchronization signal and the lamp monitor signal allowed operation of the two systems through a single set of optical ports and one reference lamp. The laboratory system was then adapted through simple changes in constants for a mult $i$-wavelength sodium 1 ine reversal systeti. In this fashion simultaneous sodium and potassium measurements of temperature could be made. The amount of sodium in coal provides a strong emission; henre, it was thought possible to make a temperature measurement as 


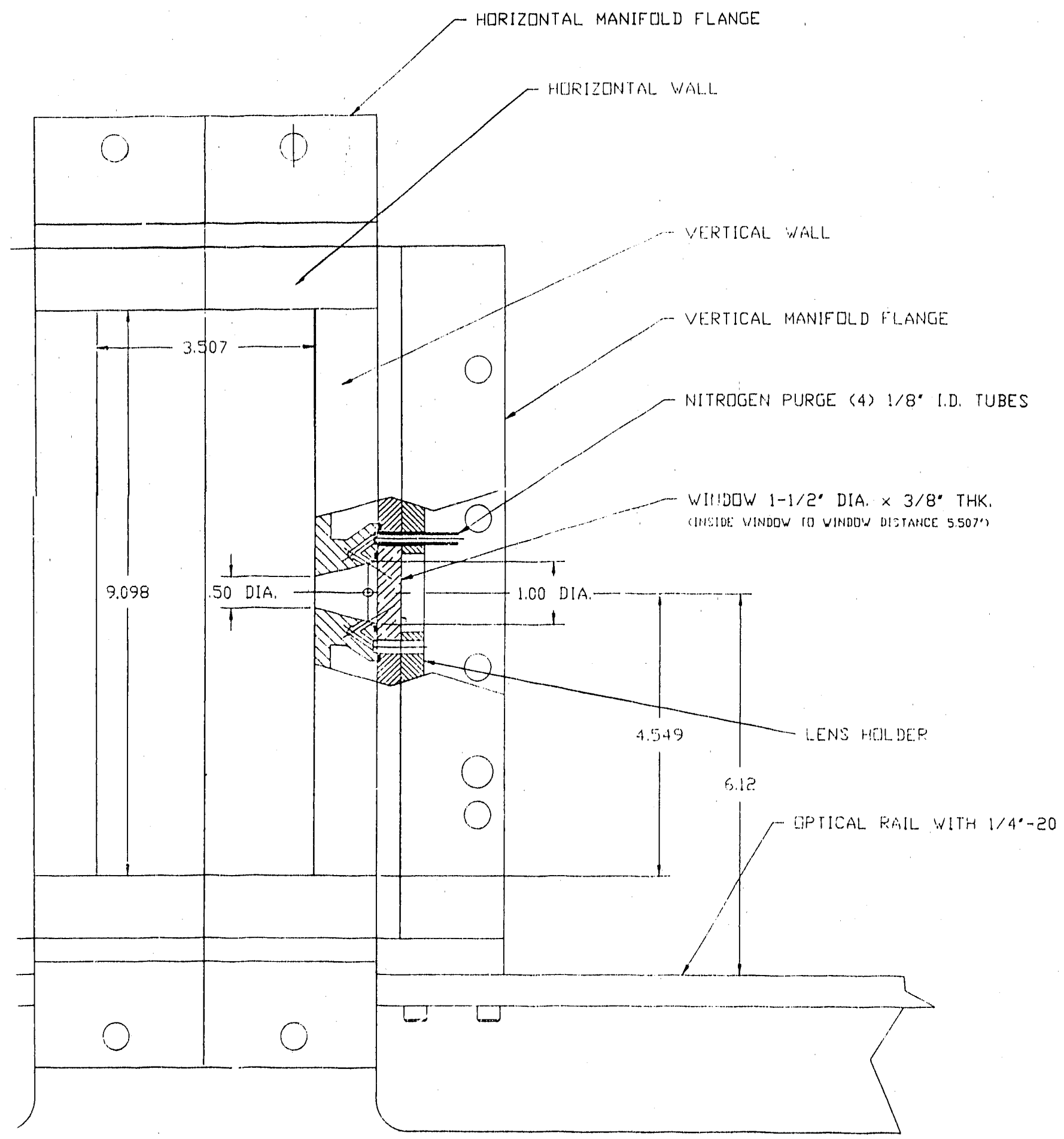

Figure 1.C.1. Design for the optical port assembly for the coal-fired combustion tests at the CDIF. 
well as test the PE/AS. Subsequent confirmation of sufficient line strength for potassium measurements and optical problems with the dual fiber mount for the third test might indicate that this was a poor decision; however, the dual arrangement worked well for the first two tests.

The first CDIF test (CFC-2) was run on March 29, 1989. The reference 1amp was operated at 18 amperes and gave an effective lamp temperature that was considerably lower than the gas temperature which is the worst situation for signal to noise considerations. The best situation for accuracy and uncertainty is for the lamp temperature to exceed the gas temperature. The effective lamp temperature is a function of wavelength due to the emissivity of the tungsten strip filament and consequently the effective temperature at the sodium wavelengths was about $100 \mathrm{~K}$ higher than at the potassium wavelengths. Because of this, valid measurements were made with the sodium multi-wavelength system but were not made with the potassium system. Inexperience of the instrument operators, with the situation of the gas temperature higher than the reference lamp temperature, caused them to believe that the systems were not working properly and unfortunately both systems were shut down for about 2.5 hours during the test. Data was obtained for about 45 minutes at the start and at the end of the test.

The preliminary sodium 1 ine reversal results are shown in Figure 1.C.2 as averages of 50 measurements taken over a time period of about one minute with bars showing the standard deviations. The averages were around $2650 \mathrm{~K}$ with standard deviations between 70 to $90 \mathrm{~K}$. On a stable benchtop flame the standard deviations would be about $10 \mathrm{~K}$. The increase in standard deviation is most likely due to increased noise because of the low reference lamp temperature and may also be due to optical problems such as vibrations in the optical mounts; however, real fluctuations of temperature or seed atom density in the coal-fired combustion flow could also contribute to the increase.

The optical windows became quite dirty and pitted during the first test with the worst degradation occurring on the lamp-side window. However, during the second and subsequent tests the windows did not suffer as much damage or dirtying and most of the problem was believed to have occurred during the many attempts at starting combustion prior to the first test. Lamp reference files and calibration files stored after test conclusion were used for all calculations 


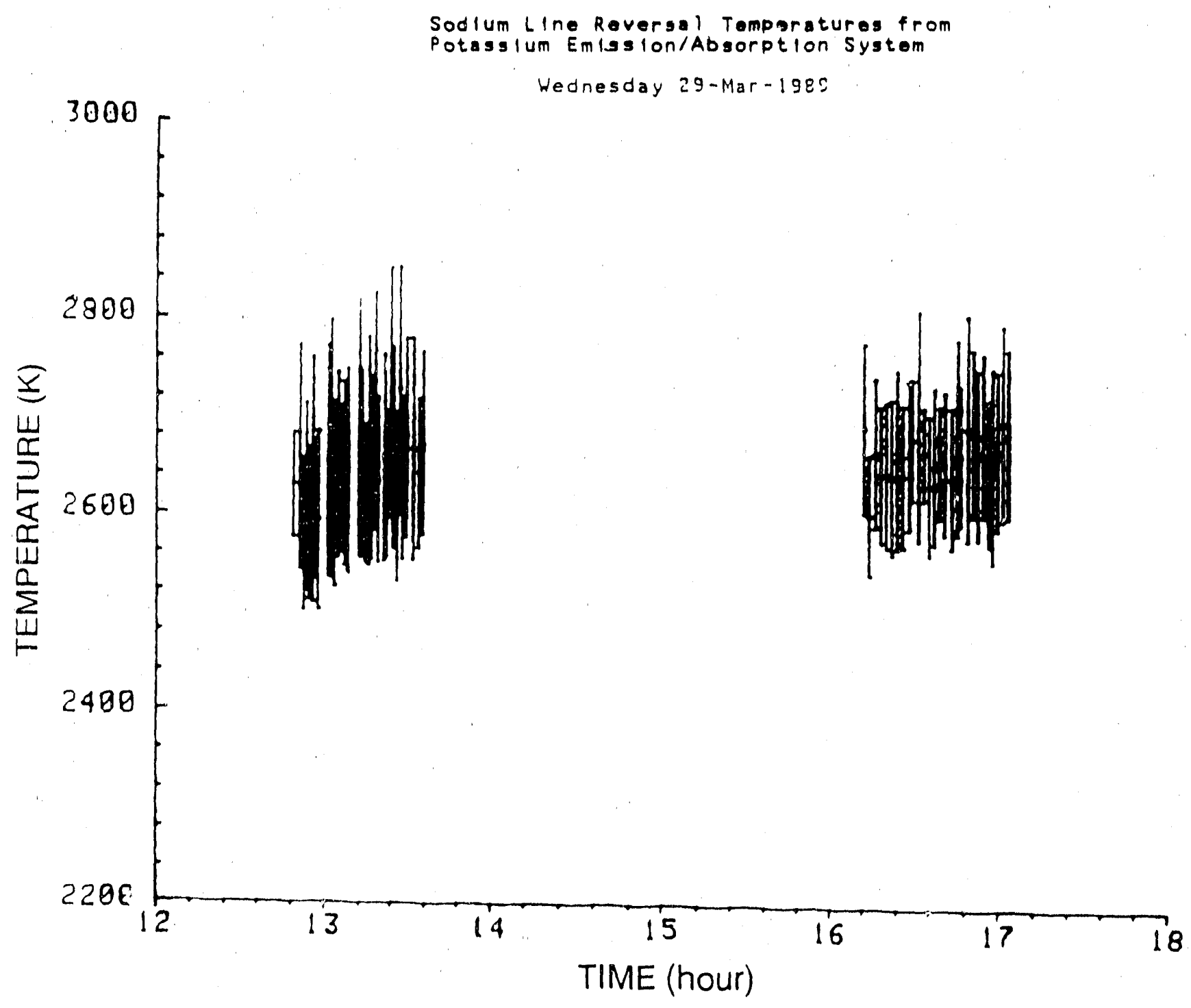

Figure 1.C.2. Sodium multi-wavelength line reversal results for the CFC-2 test on March 29, 1989. 
and if the dirtying occurred at the start of the run no bias should have been introduced by the dirty windows. Figure 1.C.3 shows pictures of the windows after Tests 1 and 2 .

For the second test on March 31, 1989 (CFC-3), the lamp was operated at 21 amperes and the results were much better because of the higher reference temperatures as shown in Figures 1.C.4 and 1.C.5 for the sodium and potassium results, respectively. Unfortunately the 1 amp burned out after only two hours of testing. Averages for the two systems were near constant at approximately $2750 \mathrm{~K}$ and agreed within $20 \mathrm{~K}$ which is remarkable and speaks well for the accuracy of the measurements. Standard deviations were lower due to the higher lamp temperature, typically 40 to $60 \mathrm{~K}$ for the sodium system and 60 to $70 \mathrm{~K}$. for potassium. The fact that the standard deviations did not drop considerably from the first test, indicates that the primary source of the temperature fluctuations is real temperature and/or atomic density fluctuations in the flow.

After meeting with CDIF personnel prior to the third test (CFC-4), a decision was made to use the laboratory PE/AS systems (previously used for sodium line reversal) for spectral scans of the emissions from the coal-fired flow. During the test on April 5, emission scans were repeatedly made over the wavelength region of $380 \mathrm{~nm}$ to $780 \mathrm{~nm}$. Each scan required about 30 minutes to collect. The scans were remarkably similar and an example scan taken from $12: 33$ to $13: 03$ is shown as Figure 1.C.6. The scans have a step appearing every $30 \mathrm{~nm}$ caused by the nonuniform response of the 500 channels of the multi-wavelength vidicon detector and the change in emission at the different times. Correcting for the vidicon response would not have improved the appearance of the data significantly. Scanning using a single channel of the detector would have yielded a smoother result but would have required considerably more time. The data shown has not had the vidicon background of about 1000 counts subtracted. The major lines have been identified on the plot as potassium (K), sodium ( $N a)$, lithium ( $L i)$, rubidium $(R b)$, calcium $(C a)$, and calcium hydroxide $(\mathrm{CaOH})$ and the waveiength scale was corrected using these lines. Lines less than $400 \mathrm{~nm}$ would not be visible due to the lack of transmission through the optical fiber. 
(a) CFC-2 Detector-Side (East)

(b) CFC-2 Lamp-Side (West) 


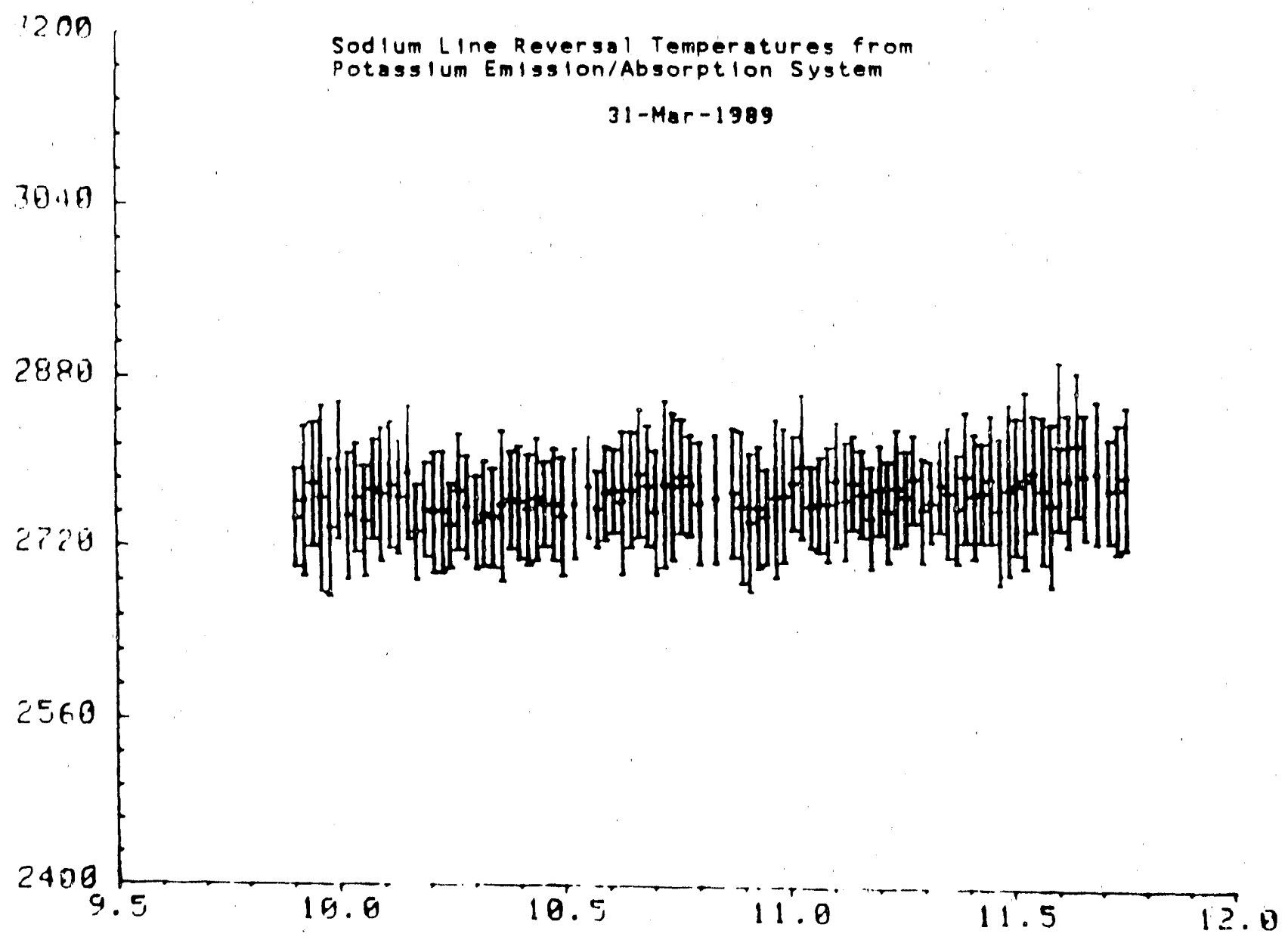

Figure 1.C.4. Sodium multi-wavelength 1 ine reversal results for the CFC-3 test on March 31, 1989. 


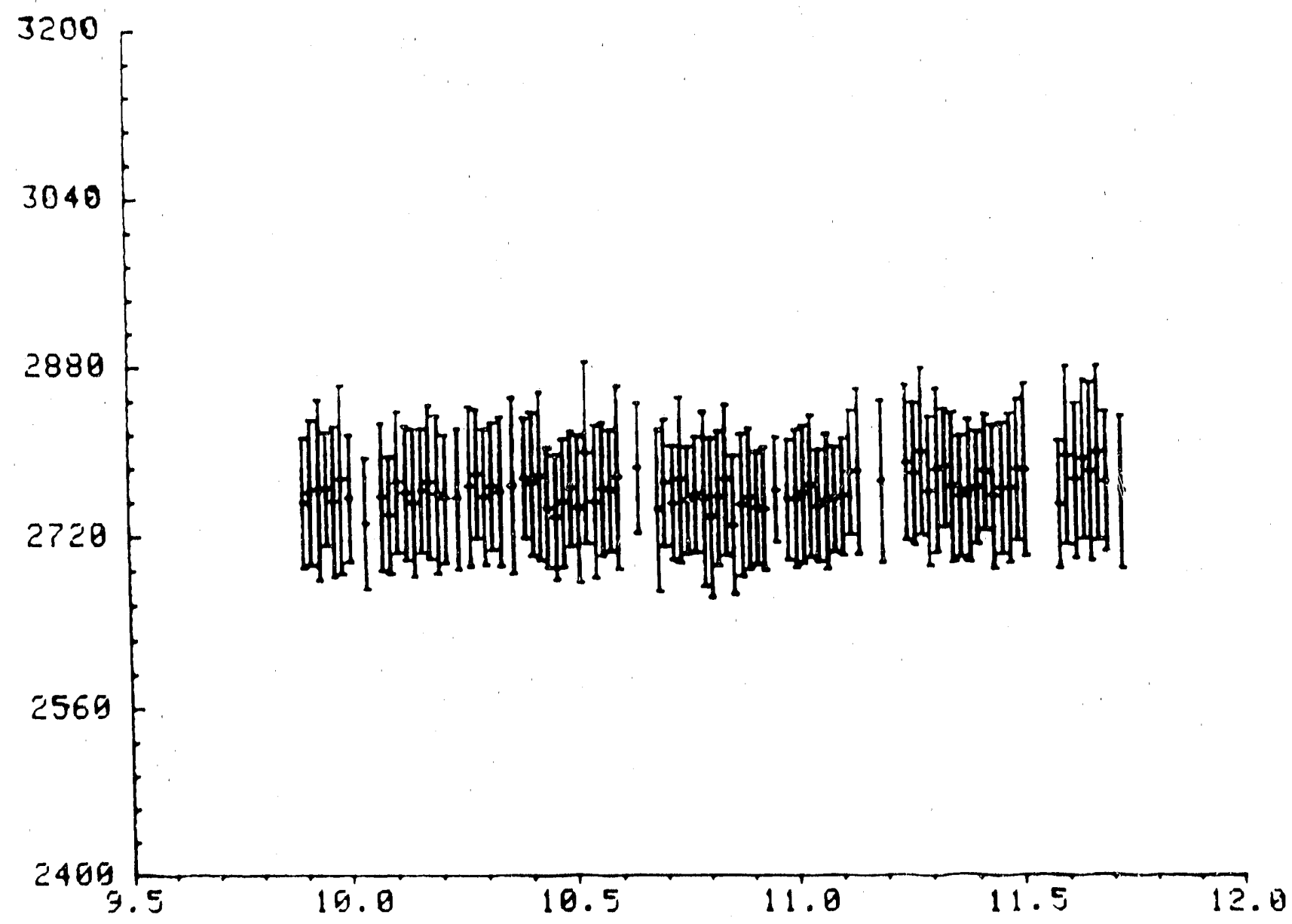

Figure 1.C.5. Potassium multi-wavelength 1 ine reversal results for the CFC -3 test on March 31, 1989. 


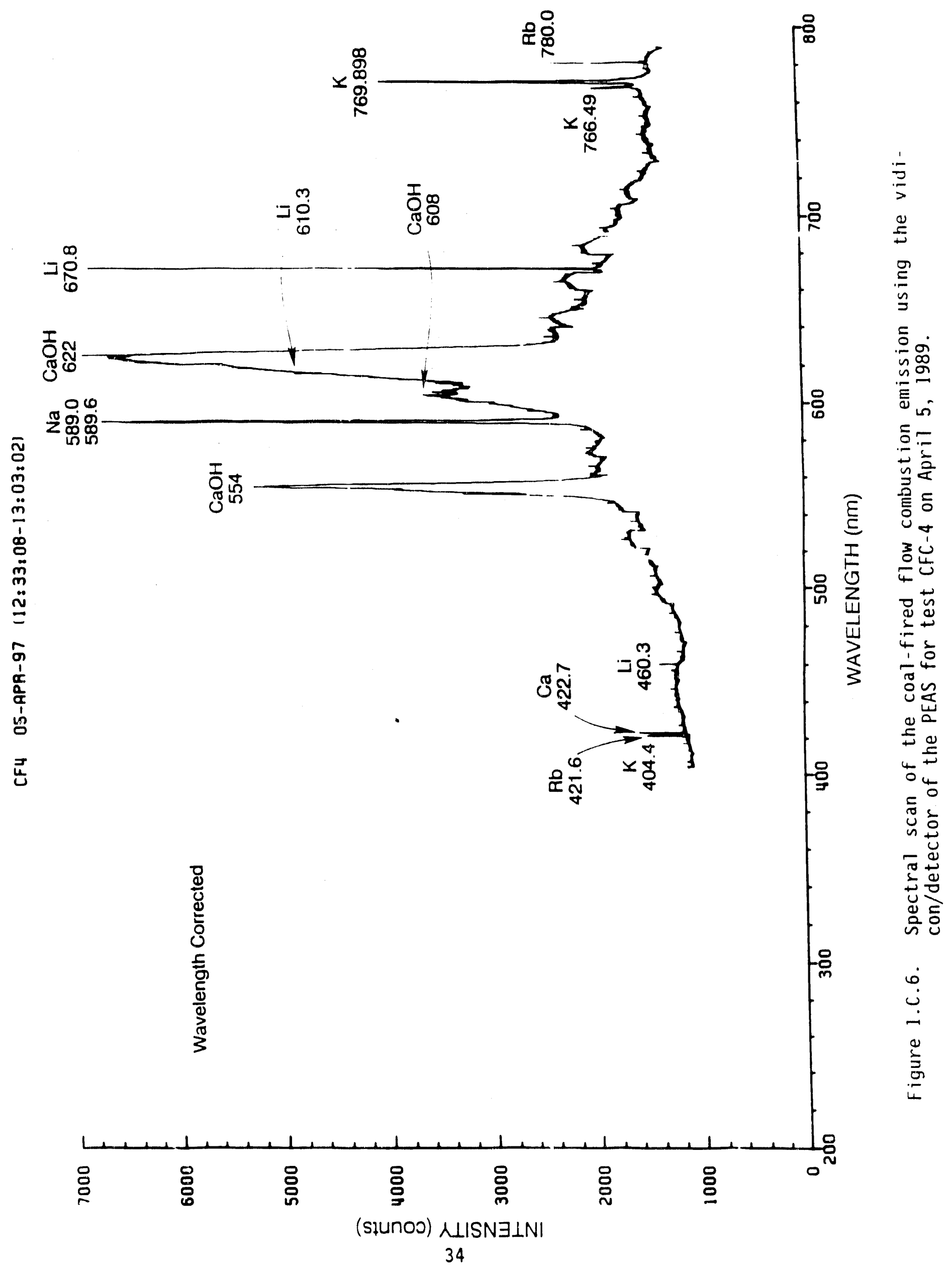


Unfortunately, valid potassium 1 ine reversal data was not obtained on the third test because of optical alignment problems. The data that was obtained would be useful in a relative sense but not in an absolute sense.

Experiments on the CDIF in Butte, Montana ended temporarily in April with water leakage in the window test section. The laboratory system was reinstalled at Mississippi State University for testing and development work. Further testing at Butte during the middle of May was straightforward and without problems. Results for the test CFC-11 on May 15 and 16, 1989 are shown as Figures 1.C.7 and 1.C.8 for gas temperature and neutral seed atom density, respectively. Similar results for May 19, 1989 (CFC-11 Repeat) are shown in Figures 1.C.9 and 1.C.10.

The field system was shipped to the DOE/CFFF facility for further testing. These tests, with full seed loading and long path lengths, provided a rigorous test of the seed number density algorithm for the worst case, i.e. extremely broad lines due to the long path lengths and high loadings. The broader the lines, the further out on the wings the measurement wavelengths must be and the far wings of the potassium lines have been shown to be non-Voigt. The current density calculation assumes a Voigt profile although it could be adapted for other profiles easily.

Few results were obtained on the LMF-4-Q test on the CFFF because of problems in switching the monochromator grating to that required for the broader lines at the CFFF. Results on the CFFF facility at UTSI on May 31, 1989, shown in Figures 1.C.11 and 1.C.12, yielded seed atomic density results an order of magnitude larger than expected and preliminary examination indicates that the cause is the non-Voigt profile of the far wings of the potassium D-lines. Work on modeling potassium line profiles is continuing. The measured temperatures were remarkably consistent with fluctuations that coincided with a water leak at about 12:45 p.m. and dips just prior to window cleaning. In retrospect, the windows should have been cleaned on a more frequent schedule.

Changes to the PE/AS software during this quarter were not significant and included adaptation of the routine for selection of measurement wavelengths to give the operator more information and minor changes in plotting routines. 


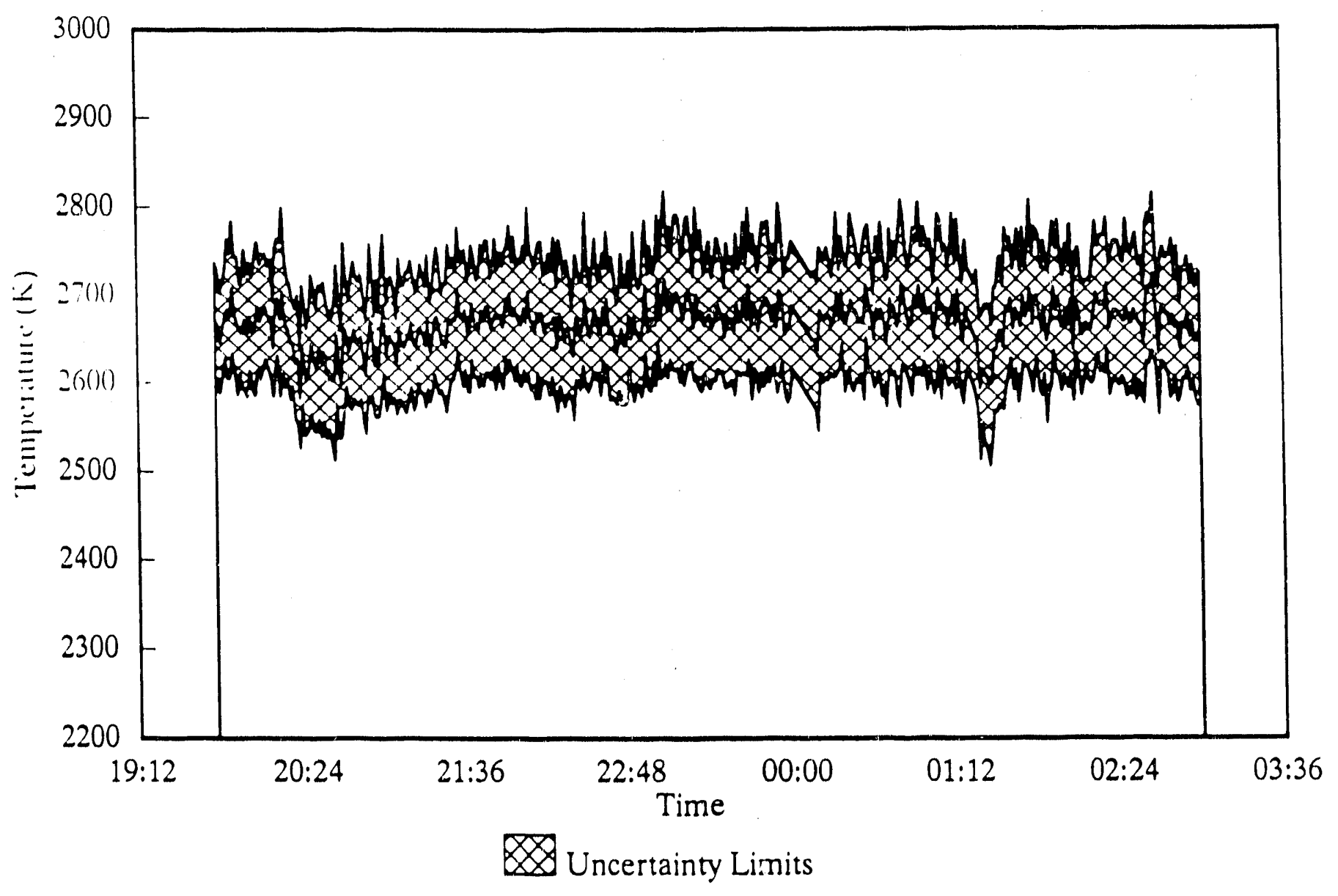

Figure 1.C.7. Potassium D-line emission absorption measurement of gas temperature for the CDIF CFC-11 test on May 15 and 16, 1989. 


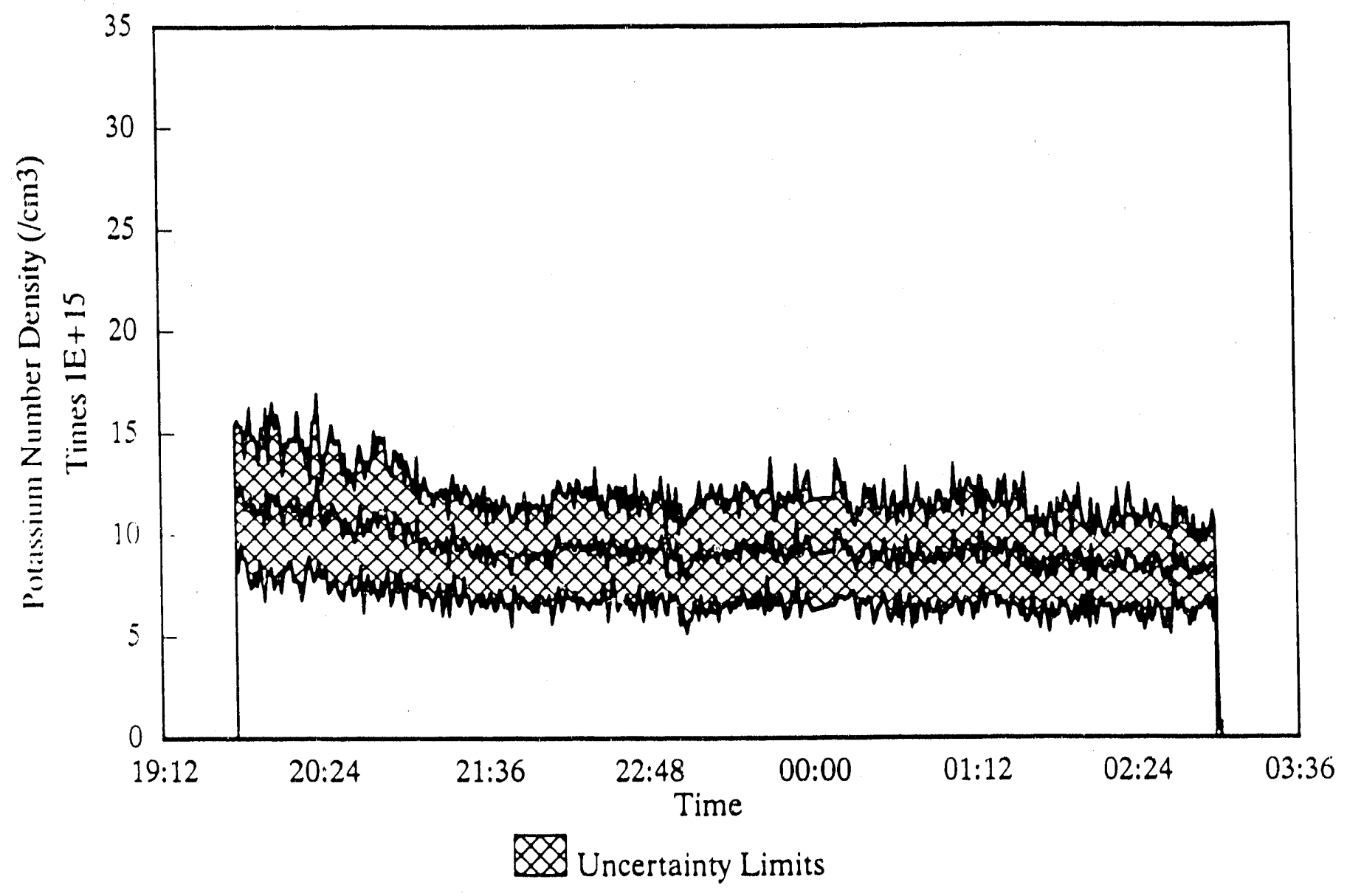

Figure 1.C.8. Potassium D-line emission absorption measurement of neutral seed atom density for the CDIF CFC-11 test on May 15 and 16, 1989. 


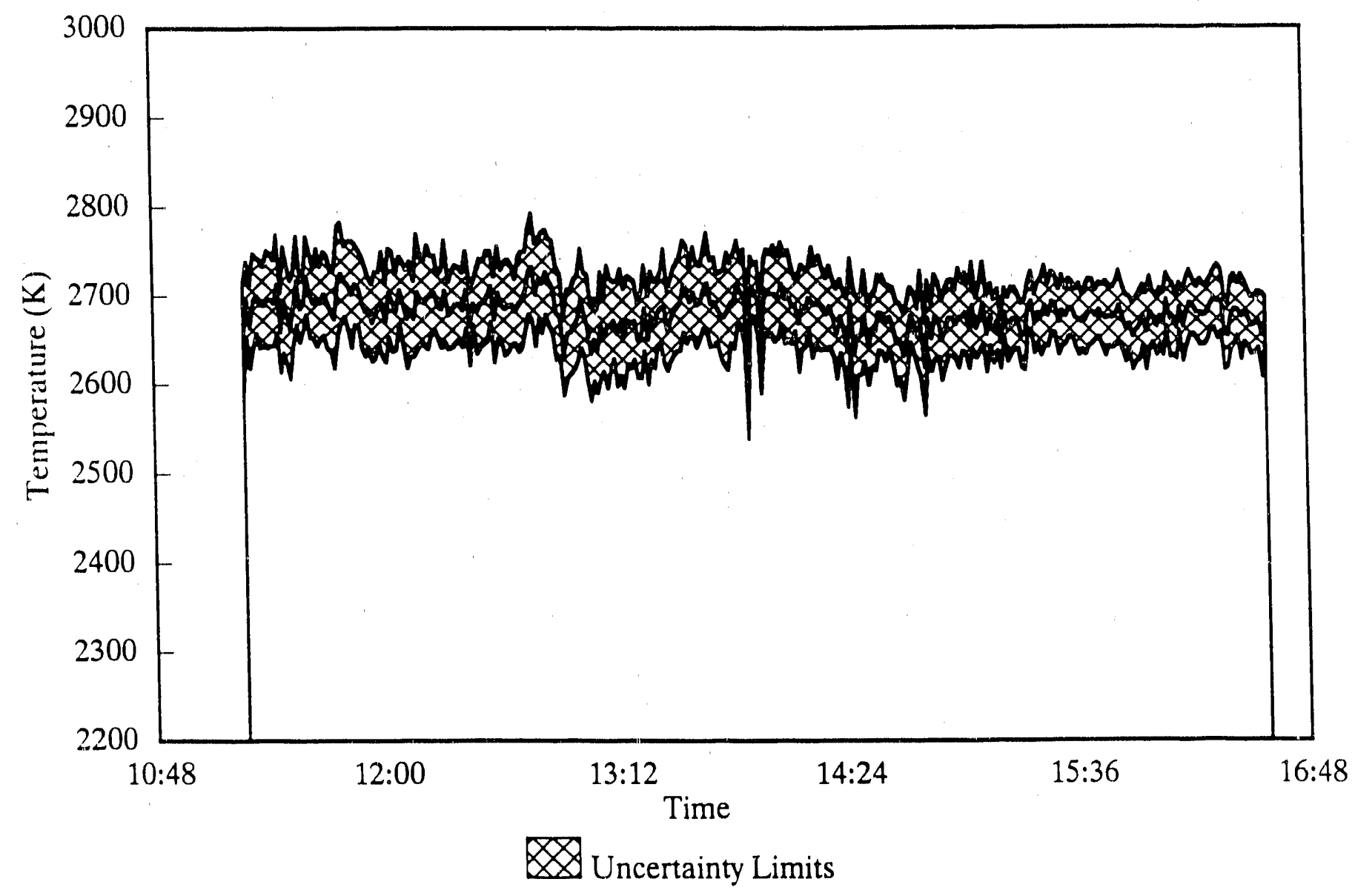

Figure 1.C.9. Potassium D-line emission absorption measurement of gas temperature for the CDIF CFC-11 test on May 19, 1989. 


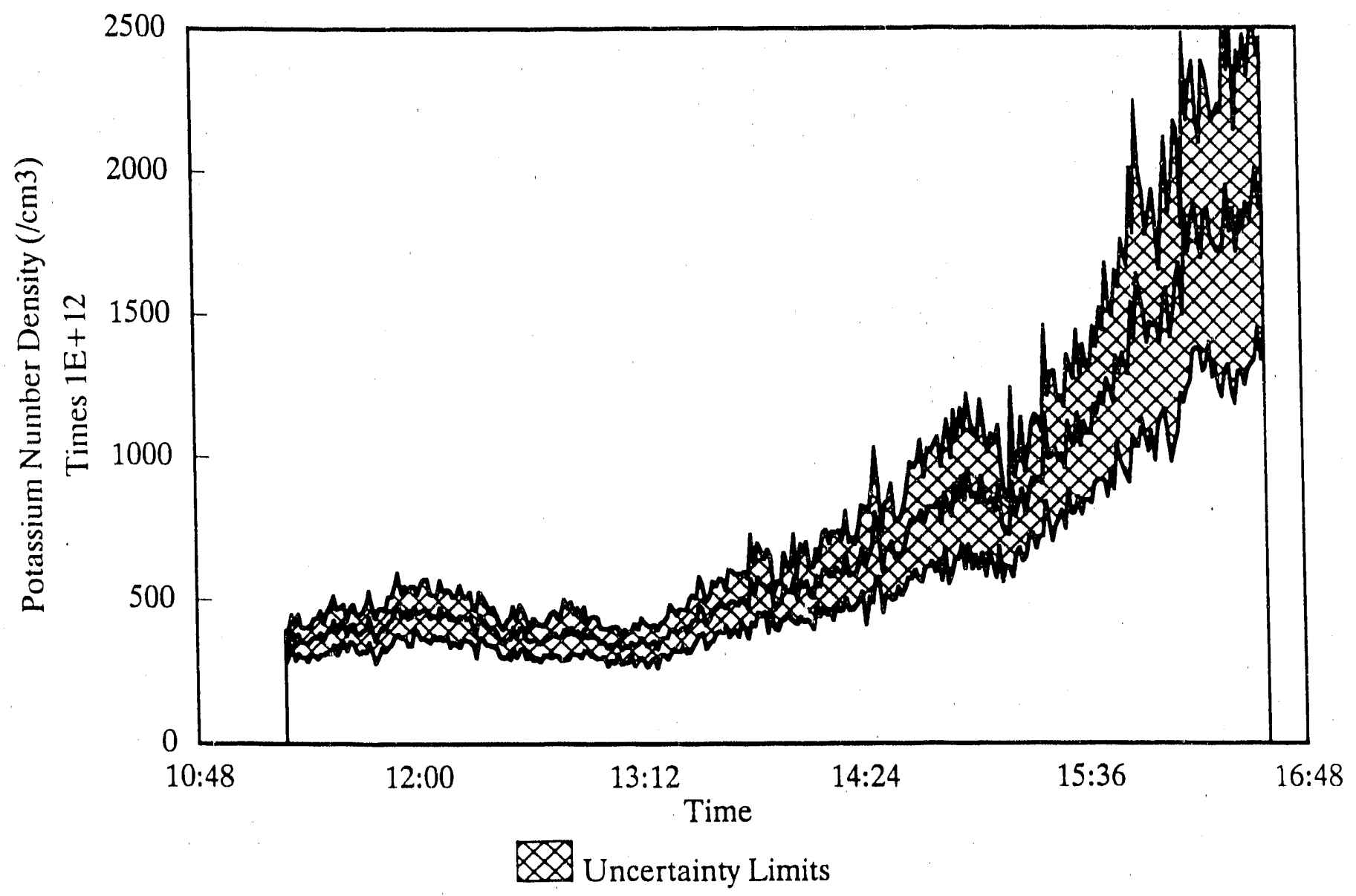

Figure 1.C.10. Potassium D-line emission absorption measurement of neutral seed atom density for the CDIF CFC-11 test on May 19, 1989. 


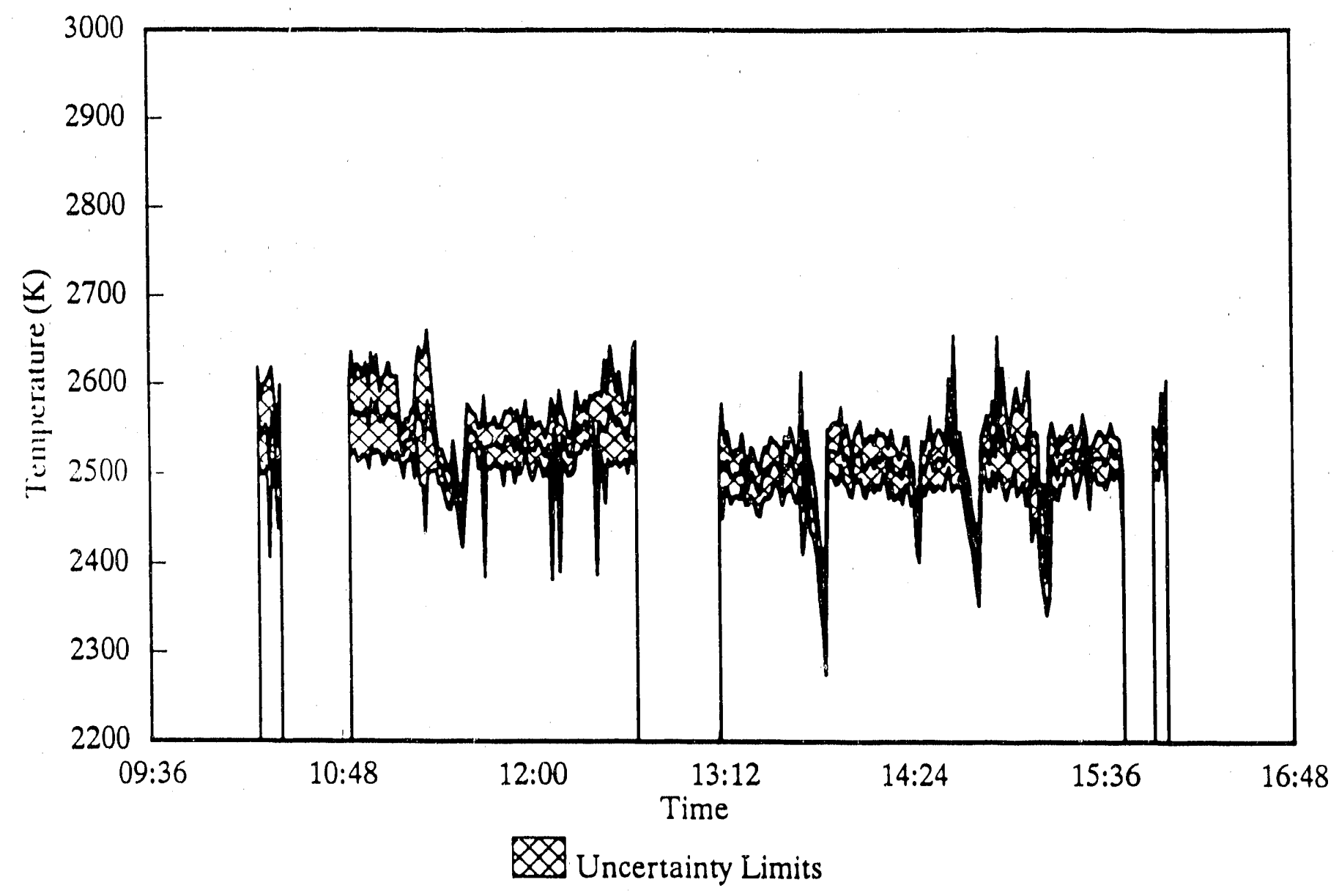

Figure 1.C.11. Potassium D-line emission absorption measurement of gas temperature for the CFFF LMF4-Q test on May 31, 1989. 


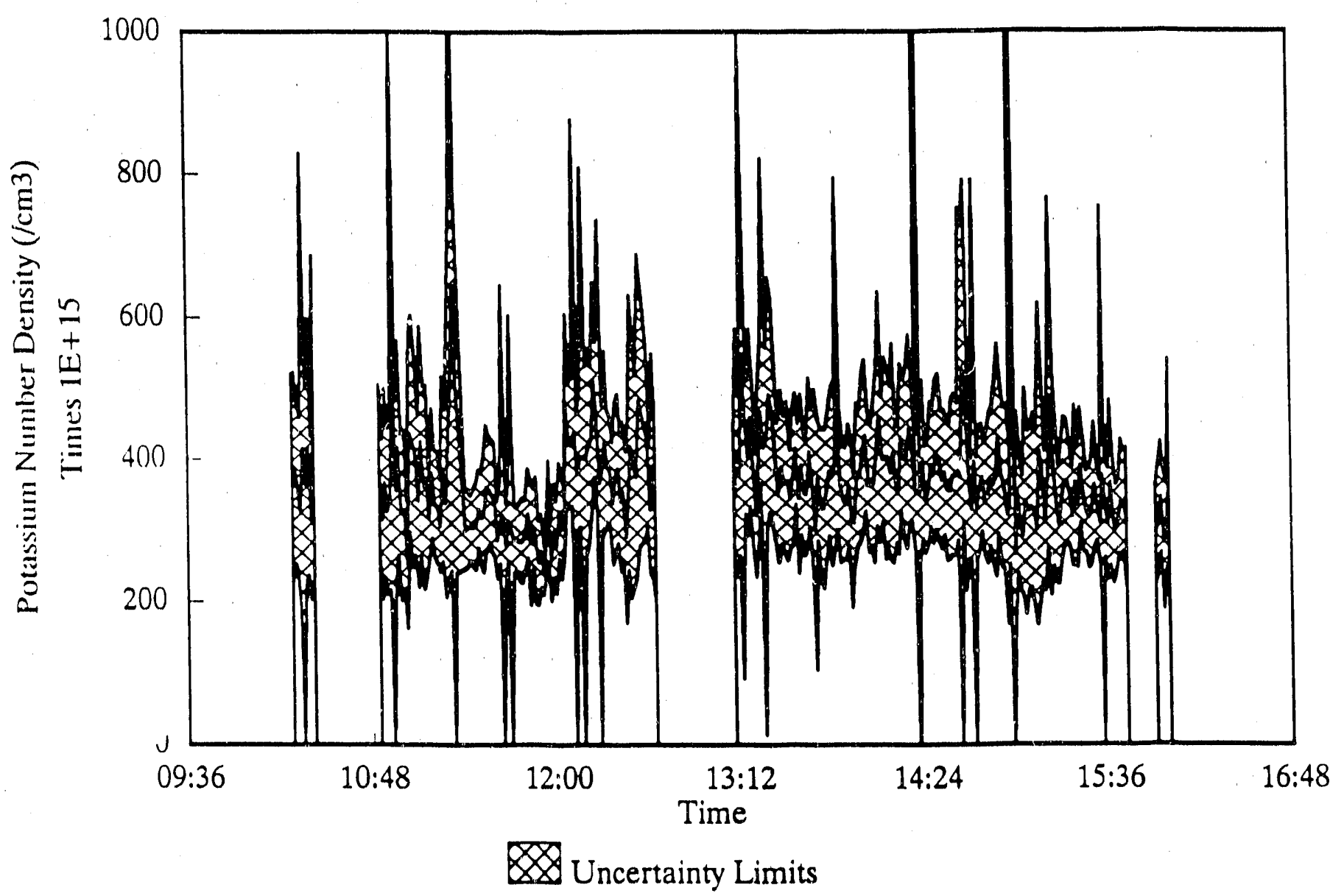

Figure 1.C.12. Potassium C-1ine emission absorption measurement of neutral seed atom density for the CFFF LMF4-Q test on May 31, 1989. 


\section{Conclusions}

Potassium seed was not injected during the CDIF tests and therefore the atomic number density algorithm was not thoroughly tested at MHD conditions. Results on the CFFF indicate problems because of the necessity for far-wing measurements due to the long path length.

Work Forecast

Work will continue on modeling far-wing potassium D-line profiles. Work still remains on switching to a different stepper motor for wavelength control and computerized slit width control is still desired. 
D. Intrusive Multi-Probe System (IMPS)

L. R. Hester

\section{Work Performed}

Several tasks were completed along with field tests conducted at CFFF with the intrusive probe support system, the intrusive lightpipe sensor and the intrusive SLR sensor. The refractory in the special test section to be added to the test stand was cured and several tests using the intrusive lightpipe sensor were conducted.

The redesigned ceramic optics holder for the miniaturized optics of the intrusive SLR sensor was completed and field tests conducted during LMF4-Q at $D O E / C F F F$. Four insertions were made at penetration 2225 of the radiant furnace with no indications of the previous problems of water leaks or window fogging taking place. Because of severe shocks occurring on the furnace structure, vibrations caused the optics to become misaligned. These were vibration shocks on the structure. The cause of the shocks was unknown. The shocks are random and have occurred during other runs but seemed to be more severe during LMF4-Q. closer tolerances in the ceramic holder will solve this problem.

The intrusive lightpipe sensor was installed at penetration 2231 of the radiant furnace to measure wall surface temperatures and to evaluate the effects of the higher temperature on the lightpipe sensor system. Eight successful insertions were made with ine only effect being a shorter measurement time of 25 seconds compared to 60 seconds in the superheater. The sensor was moved upstream to penetration 2225. Nine insertions were made at this penetration with seven being successful. Again the only effect of the higher temperature was to cause a shorter measurement time. A typical wall surface temperature at penetration 2225 is shown in Figure 1.D.1. The variation is probably caused by the fact that the probe was not as close to the wall as it should have been. jubsequent tests will be conducted where the probe position is more accurately known.

The design for the air drive insertion system was completed and all of the components were ordered. 


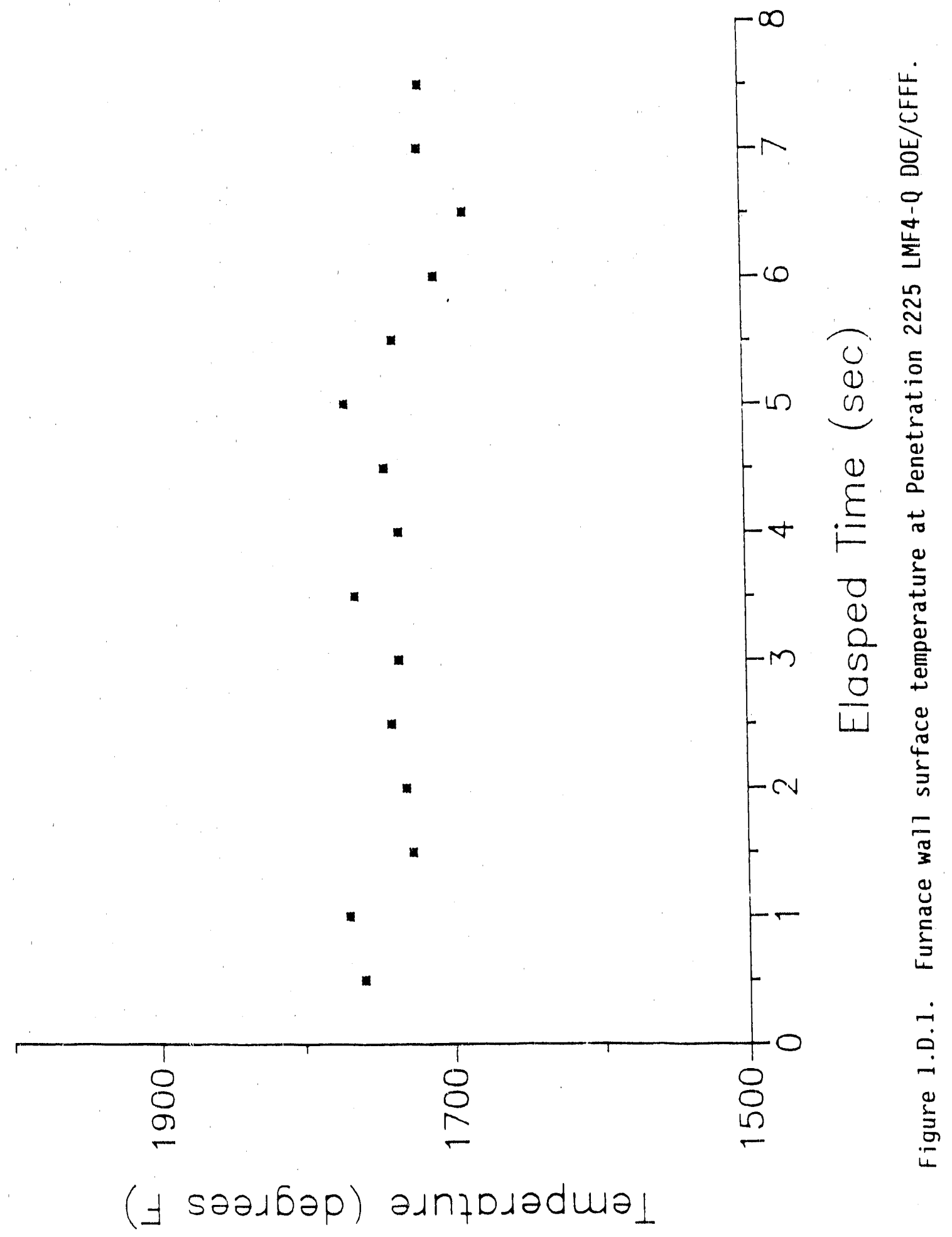




\section{Conclusions}

Based on the field test conducted during LMF4-Q at CFFF, the inirusive lightpipe sensor and support system can withstand the higher temperatures of the furnace and successfully provide reliable wall surface temperature. Also the basic concept of the intrusive SLR sensor was proven to be viable with the four insertions made at penetration 2225 during LMF4-Q at CFFF.

Work Forecast

Reworking the intrusive SLR sensor's optics holder to provide the required alignment tolerances has been initiated and will be carried through the next work phase. The air drive system will be installed on the intrusive support system upon receipt of all components. Further calibration and verification tests with the intrusive lightpipe sensor will be conducted in the test stand special test section. 
E. Faraday Rotation System (FRS)

L. E. Bauman

Work Performed

Work is essentialiy complete on the basic routines for computerized data collection. The routine for input of data from the far infrared detectors is complete. For this routine, the analog output from the lock-in amplifier is input to the analog-to-digital interface board of the computer. Control of the grid polarizer through a rotational stage and computer-controlled stepper motor has been completed. The current hardware gives 100 steps per degree which is finer than is required considering the error bands that arise because of fluctuations in the laser, detector, and plasma source.

Difficulties continue to arise with the computer because of its age and perhaps incompatibilities between the operating system and packaged software routines. It is hoped the seven year old I.SI-11/23 computer will be replaced with an IBM-compatible AT computer.

Preliminary work on characterizing the magnetic field for the pole faces constructed for the Faraday rotation experiment has been completed. The measured field strength at maximum power is 1.5 Tesla.

Work on a seeded flame that will provide a measurable rotation signal has begun.

Conclusions

System assembly work is almost complete.

Work Forecast

Data collection and calculation routines will be merged into a single package. 
F. Multi-Purpose Imaging System (MPIS)

$J$. S. Lindner and R. Lenge 7

\section{Work Performed}

Work continued on the laser-induced fluores :nce of potassium in the laboratory $\mathrm{flame}$. Previous work on the $5 p^{2}-4 s^{2}$ transition at $405 \mathrm{~nm}$ revealed extremely rapid excited state quenching. 1 An attempt was therefore made to determine if the energy was being transferred to other states. Examination of the visible wavelength region using the monochromator/photomultiplier tube assembly did not reveal any other fluorescence lines. This result although not unexpected is somewhat unfortunate, since as described elsewhere 2 it is most advantageous to study three level schemes where background effects, such as scattering and thermal radiation, can be discriminated against.

The ability to image the potassium atoms using the $5 p^{2}-4 s^{2}$ transition is currently limited by low incident laser powers. Figure 1.F.1 illustrates the LIF of $K$ in the laboratory burner. The laser beam is clearly visible over the top of the burner. Note that, as opposed to the sodiunilimages presented earlier ${ }^{3}$, the beam in Figure 1.F.1 is not expanded into a thin sheet using the cylindrical optics. Attempts to use these optics produced intensities from the LIF only. slightly above the dark current on background readings of the intensified camera. The problem with the low laser intensities is that in order to produce the $405 \mathrm{~nm}$ excitation wavelength the output of an infrared dye, $\lambda_{0} \sim 810 \mathrm{~nm}$, which is itself an inefficient medium, must be frequency doubled.

\section{Conclusions}

Experiments using an underexpanded laser beam at $405 \mathrm{~nm}$ indicated that images of potassium can be obtained. Other studies were conducted in order to determine if the excited state energy of the $3 p^{2}-4 s^{2}$ transition was transferring to other states. No crossing was observed.

\section{Work Forecast}

[fforts are currently in progress to increase the incident laser power at $405 \mathrm{~nm}$. A number of schemes involving mixing are under consideration. 


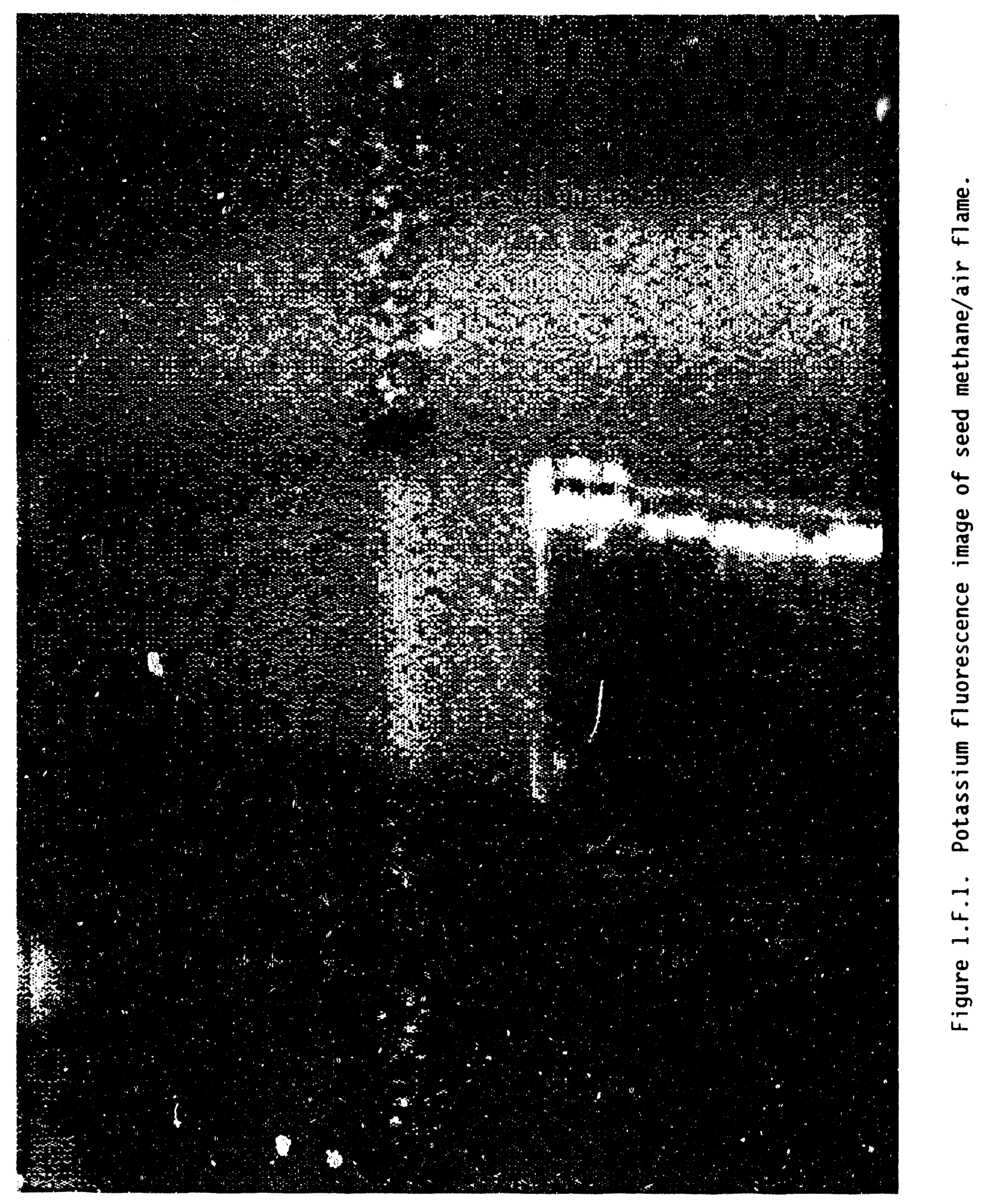




\section{References}

1. Lindner, J. S., and Lengel, R. K. 1989. DIAL Quarterly Technical Progress Report FE-15601-36:37.

2. Lengel, R. K., and Crosley, D. R. 1978. J. Chem. Phys. 68:5309.

3. Lindner, J. S., and Lenge1, R. K. 1988. DIAL Quarterly Technical Progress Report FE 15601-35:50. 
Task 2. Test Stand Operations: J. A. Etheridge

A. Test Stand Modifications: Two additional runs were needed for curing the refractory lining in a test section that was constructed for use with the probe system. This section allows the MCP system and an intrusive probe to view the same wall location within the test stand simultaneously. It was used for two of the probe test runs.

B. Computer Control Up-grade: The PMIS software was installed on the A400. Development of the PMIS software began. PMIS is a software package marketed by Bradley Ward, Inc. It is a general purpose data collection and display package which must be tailored to the particular application by the user. Additional software had to be written for things not handled by PMIS.

C. Test Stand Runs: Thirteen test runs (summarized in Table 2.C.1) were completed during this quarter. The total run time was approximately 100 hours. $\mathrm{Six}$ runs were for the Gas Analysis System. Shakedown of the $\mathrm{SO}_{2}$ measurement system was of particular interest. Four test runs were for the Intrusive Multi-Probe System. The first probe tested was an SLR probe. A ceramic part of this probe cracked early in the test and the run was aborted. The three additional probe runs were for wall temperature measurements. During the final two of these tests the probe measurements were compared to MCP measurements. This was made possible by using a specially constructed test section which was completed and installed in the test stand during this quarter. Three additional runs were for an optical correlation experiment. 
Table 2.C.1. MSU test runs, April - June, 1989.

\begin{tabular}{cccccc} 
NO. HOURS & DATE & INSTRUMENTS & CONDITIONS & COMMENTS \\
\hline 1 & 8 & $04 / 5 / 89$ & None & Refractory cure \\
2 & 9 & $04 / 11 / 89$ & Gas Analysis & Seed/Slag Injection & \\
3 & 8 & $04 / 17 / 89$ & Gas Analysis & Seed/Slag Injection & \\
4 & 8 & $04 / 25 / 89$ & Gas Analysis & Seed/Slag Injection & \\
5 & 8 & $05 / 04 / 89$ & Optical Correlation & Clean Fuel & \\
6 & 6 & $05 / 09 / 89$ & Gas Analysis & Seed/Slag Injection & \\
7 & 8 & $05 / 11 / 89$ & Gas Analysis & Clean Fuel & Shut Down- \\
8 & 9 & $05 / 22 / 89$ & Optical Correlation & Clean Fuel & Water Leak \\
9 & 6 & $05 / 26 / 89$ & Intrusive Probe & Clean Fuel & Combustion \\
10 & 9 & $06 / 01 / 89$ & None & Final Refractory & Cure \\
11 & 7 & $06 / 12 / 89$ & SLR Probe & Clean Fuel & Probe Cracked \\
12 & 8 & $06 / 15 / 89$ & MCP, Probe & Clean Fuel \\
13 & 9 & $06 / 20 / 89$ & MCP, Probe & Clean Fuel
\end{tabular}


Task 3. Technical Support for National MHD Program: R. D. Benton

\section{A. Field Measurements}

A series of PE/AS temperature measurements at CDIF, which were begun March 29, continued in April and May. Details of these measurements are given in Task 1.C of this report.

Velocity measurements were made with the LDV system at the same point during this series of tests. On May 3 and 9 the LDV system was configured to measure the velocity which was about 700 meters/second at the centerline of the test section. Due to a problem with the LDV burst spectrum analyzer (BSA), insufficient data were obtained to provide statistical certainty to the measurements. New circuit boards were obtained from the BSA manufacturer and the LDV system was repaired.

The LMF4-Q test at CFFF was supported with the PE/AS, MCP, TCLT, and IMPS systems. The data results are reported in MSU/DIAL Data Report Vol. 9, No. 1 which is available on request.

Velocity, temperature, and gas analysis measurements are scheduled at CDIF next quarter. These measurements will be made on the diffuser. Support of the LMF4-R test at CFFF is scheduled for August. A number of DIAL instruments are scheduled for this test.

\section{B. Field Tests/Instrument Modifications}

The new remote window changing apparatus was tested at CFFF during the LMF4-Q test. It operated as expected. This device allows remotely changing dirty windows and is required in locations like CDIF where the windows cannot be manually changed or cleaned during a test. Plans are to use this device at CDIF during the next quarter.

The CARS system will be tested at CFFF during the LMF4-R test series.

C. Mobile Instrument Laboratory

One PS-2 type computer has been delivered. The other computer is expected during the next quarter. 
Task 4. Project Management

This is an ongoing task considered up to date with the submission of this report. 
Task 5. Technology Transfer

Preliminary discussions of a proprietary nature were held with Dow Chemical for a new project. 

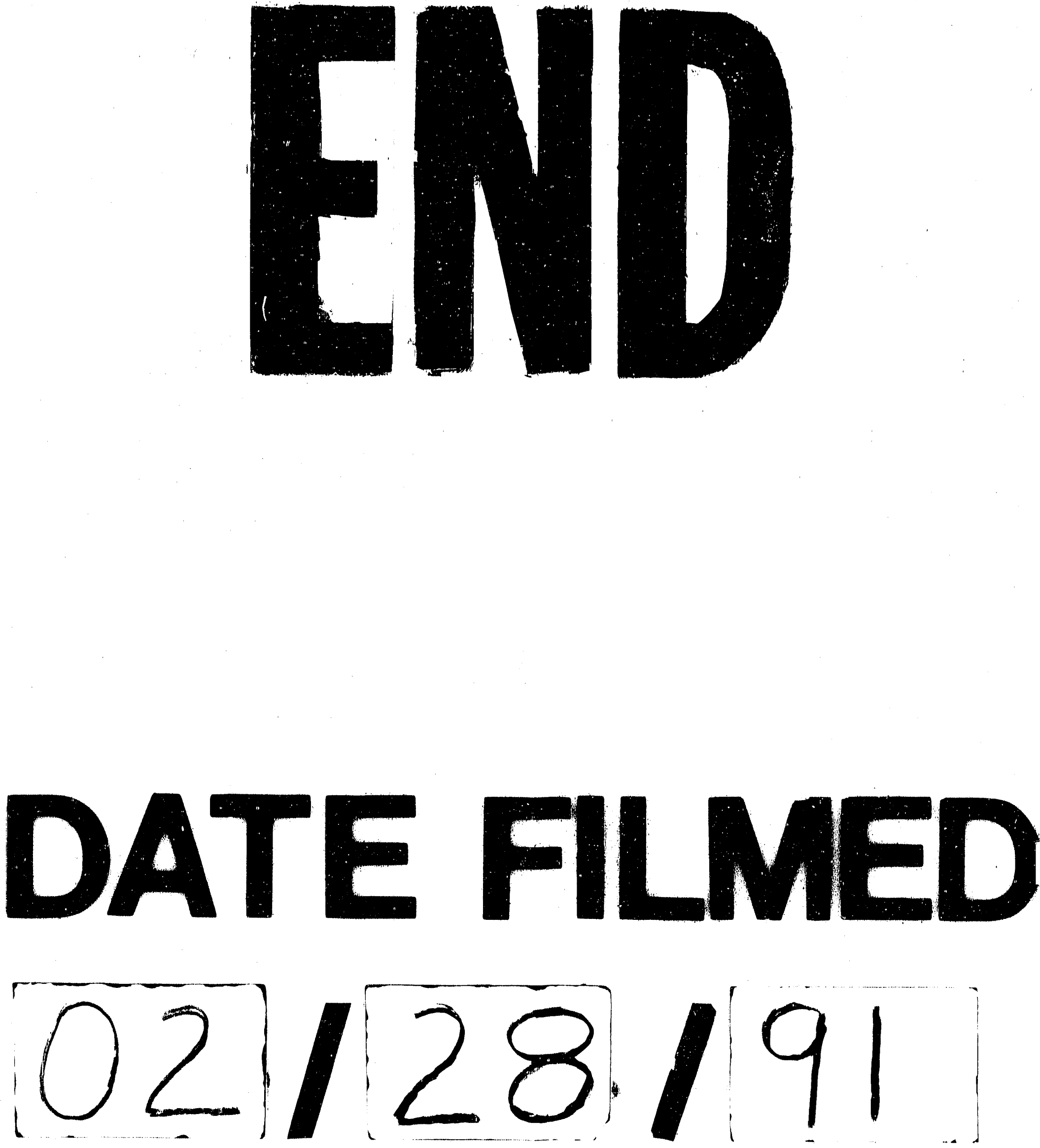
